\title{
Estimation of Male Reproductive Success of Marine Fishes
}

\author{
Edward A. Trippel \\ Fisheries and Oceans Canada, Biological Station \\ St. Andrews, New Brunswick E5B 2L9 Canada
}

\begin{abstract}
The subject of reproductive potential of fish populations is dominated by studies on the female gender. Studies on male reproduction are relatively few, but have increased in number during the previous decade. The objectives of this contribution were to describe and quantify the reproductive traits that make up the viable sperm production of a population. Some of these reproductive traits were easily measured from wild fish (e.g., mature testes weight), and others were more easily measured on captive fish (e.g., fertilization potential and sperm motility). Results of laboratory and field studies were then integrated to generate estimates of viable sperm production of a fish stock. A number of experimental protocols have been employed over the years to assess male fertility. The strengths and weaknesses of the different experimental approaches were reviewed and appropriate recommendations given towards establishing standardized protocols. Although the review is broad in nature, and includes references to a number of marine fishes, it concentrated on exploited species that occur in the North Atlantic and Baltic Sea within the taxonomic groups gadoidae, pleuronectoidae and clupeidae (Clupeiformes). In addition, published data on male reproductive traits of species in these taxa were tabulated and summarized. The terms of interest included sex ratio, maturity state, testes weight, sperm fertilization potential (artificial fertilization and paired mating), sperm density, sperm motility and paternal effects on early life history traits.
\end{abstract}

An equation for determinate spawners was described that quantifies a population's viable sperm production using data on adult body characteristics and associated quantity and quality of sperm. The equation was used to establish time series of viable sperm production for Atlantic cod (Gadus morhua) of Newfoundland and Labrador. Results indicated on average 1600 billion viable sperm were released to produce one recruit at age 3 years but with substantial variation among years in relation to changes in stock composition and growth as well as stock size. Distinct peaks in the number of viable sperm in 1981 and 1986 corresponded to distinct peaks in the number of age 3 recruits in those same years.

Keywords: Atlantic cod, fertilization potential, genetics, larvae, mating success, maturity, paternal effects, spawning, sperm competition, sperm density, sperm motility, stock reproductive potential

\section{Introduction}

The subject of reproductive potential of fish populations is dominated by studies on the female gender. Studies on male reproduction are relatively few, but have increased in number during the previous decade. The concentration on female processes within a population is obvious, given they control the number of eggs produced and its potential cohort members. Quantity of spawned eggs has been positively correlated with maternal length, age and nutritional condition (Bagenal, 1973; Kjesbu et al., 1991, 1996). Variability in size and quality of eggs influences early life success and presumably recruitment (Blaxter and Hempel, 1963; Bengtson et al., 1987; Chambers, 1997; Pepin et al., 1997; Trippel, 1998;
Lambert et al., 2003). What then is the male's role in determining recruitment success? In the extreme case, if there were no males, no eggs would be fertilized. Is population sperm production and the availability of spermiating males always sufficiently abundant to fully fertilize each female's egg batch (Gilkey, 1981; Markle and Waiwood, 1986; Howell et al., 1991; Marconato et al., 1997)? Mating strategies of species differ and these questions may be inter-related with spawning behaviour, such as breeder dominance, spawning shoal structure, promiscuity, and fertilization tactics (Stockley et al., 1997; Takborsky, 1998). Although to assess mating strategies in wild spawning assemblages is important, it is beyond the scope of this contribution and in itself is a relatively unstudied area of fishery science (Shapiro and 
Giraldeau, 1996). This contribution will focus on male reproductive potential with the intention of developing an index or measure of reproductive potential that could be used in place of male spawning stock biomass in stock-recruitment studies (Marshall et al., 1998; Trippel, 1999; Cardinale and Arrhenius, 2000).

The objectives of this contribution are to describe and quantify the reproductive traits that make up the viable sperm production of a population. Some of these reproductive traits can be easily measured from wild fish (e.g., mature testes weight), and others are more easily measured on captive fish (e.g., fertilization potential and sperm motility). Results of laboratory and field studies can then be integrated to generate estimates of viable sperm production of a fish stock. A number of experimental protocols have been employed over the years to assess male fertility. The strengths and weaknesses of the different experimental approaches will be reviewed and appropriate recommendations given towards establishing standardized protocols. Although the review is broad in nature, and includes references to a number of marine fishes, it will concentrate on exploited species that occur in the North Atlantic and Baltic Sea within the taxonomic groups gadoidae, pleuronectoidae and clupeidae (Clupeiformes). In addition, published data on male reproductive traits of species in these taxa will be tabulated and summarized. The terms of interest include sex ratio, maturity state, testes weight, sperm fertilization potential (artificial fertilization and paired mating), sperm density, sperm motility and paternal effects on early life history traits. At the end of the paper, an equation will be presented that integrates several of these male traits to compute total viable sperm production of a fish population. An example that applies available data on Northwest Atlantic cod (Gadus morhua), in particular that of the Newfoundland and Labrador stock, is presented.

\section{Experimental Techniques to Evaluate Male Reproductive Potential}

\section{Sperm Fertilization Potential}

Given the shifts in fish populations towards earlier ages and smaller sizes at sexual maturity in recent years (Fig. 1) (Trippel, 1995; Trippel et al., 1997a; Cardinale and Modin, 1999) and, in some cases, reduced nutritional condition (Lambert and Dutil, 1997a; Marshall et al., 1999; Rätz and Lloret, 2003), is it possible that the ability of spermatozoa to fertilize eggs has also become reduced, and that relatively fewer eggs are being fertilized? Do only specific segments within a stock have sperm good enough to fertilize eggs?

Apart from the morphological and energetic characteristics of spermatozoa (e.g., head size, adenosine triphosphate (ATP) storage levels and biochemical composition of the semen; Billard, 1986; Jamieson, 1991; Lahnsteiner et al., 1996; Lahnsteiner and Patzner, 1998; Glogowski et al., 1999) it is of use and perhaps more relevant to simply evaluate whether sperm vary in their capacity to fertilize eggs (Figs. 2 and 3). This type of experiment can be conducted at sea or in the laboratory, and assists in gauging relative sperm viability among, for instance, virgin and repeat-spawning, scrawny and plump, or young and old males. If a gradient of fertilization capacity exists in relation to a body dimension, the relationship could be applied to the male segment of a stock and yield an appropriate disaggregated weighting of reproductive potential (Trippel, 1999; Murawski et al., 2001).

\section{Fertilization trials in diluted semen solutions}

\section{a) Selection of males and short-term gamete storage}

Experiments with sperm should begin as soon as possible after stripping, at least within the first 6-8 $\mathrm{hr}$, as sperm quality declines during the course of an experiment. After eight hours, there is a greater risk that storage time could reduce sperm quality (i.e., related to many factors such as species, initial quality and storage conditions). In rainbow trout (Oncorhynchus mykiss), sperm quality and fertilization ability were already reduced after $2 \mathrm{hr}$ storage (Lahnsteiner et al., 1997). Ideally, controls should be conducted at the beginning, middle and end of an experiment to test for a decline in sperm quality. Care should be taken not to include urine in semen samples, as this can activate sperm motility (region around the genital pore should be wiped dry before expressing milt and catherization of ureter prior to stripping in some cases is also recommended) (Rana, 1995; Dreanno et al., 1998). Urine- and fecescontaminated samples should be discarded. Syringes may also be used to collect semen, their volume dependent on species and experimental design. Semen (defined as sperm plus seminal fluid) should be stored in clean, dry beakers or tubes and kept cool, either on ice or at the desired temperature at which the experiment is conducted. Colder temperatures will maintain quality longer, though this could have an impact on motility when sperm are subsequently mixed in water of a higher temperature (Vladic and 


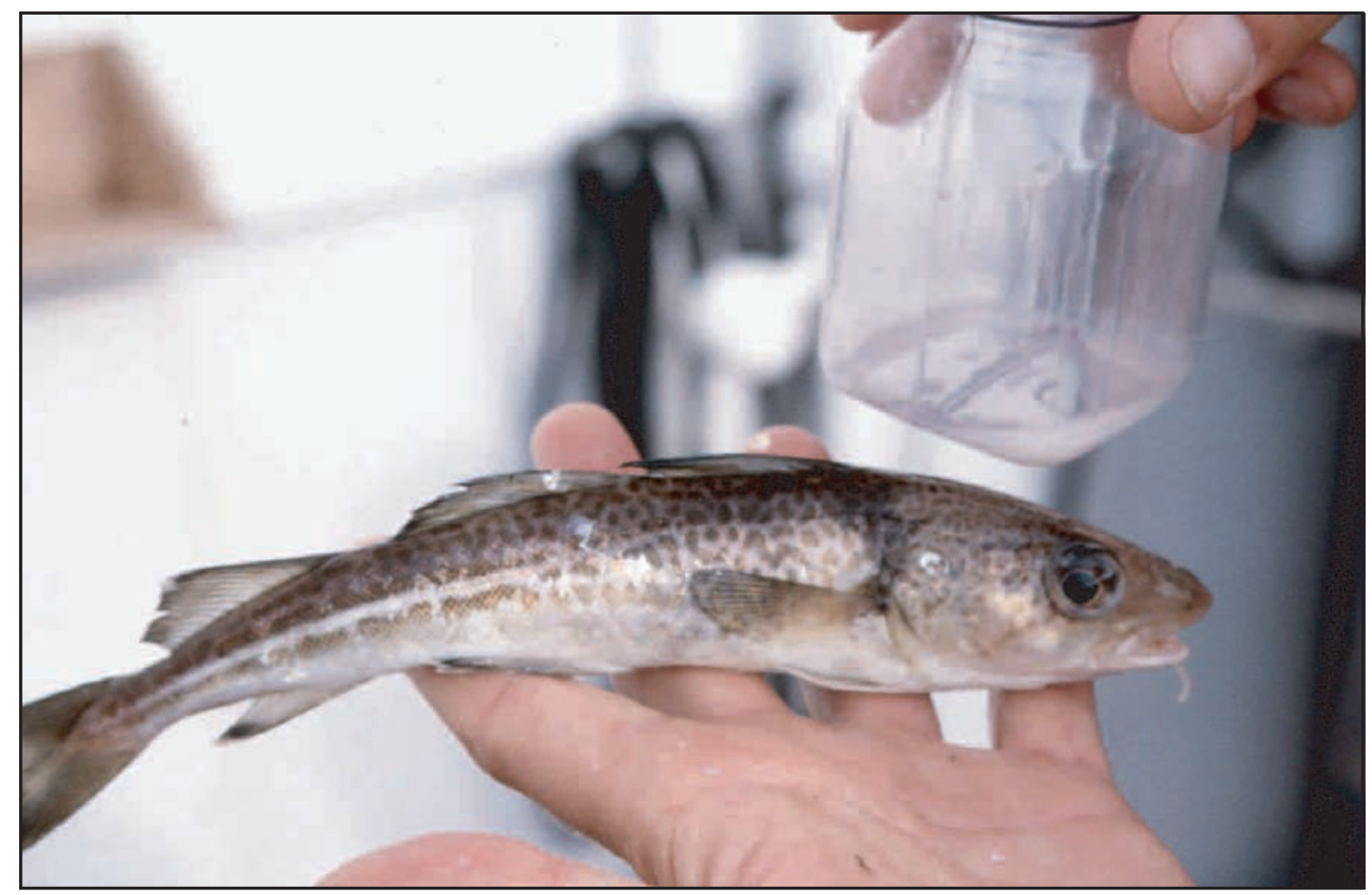

Fig. 1. Photograph of a $22 \mathrm{~cm}, 65 \mathrm{~g}$ precocious male cod (Gadus morhua) of the Central Baltic Sea and its stripped semen, August 2001. Source: E.A. Trippel.

Jaervi, 1997). Containers holding sperm should be covered (e.g., with foil or waxed film) to prevent accidental entry of water and pre-mature activation of some portion of the storage vessel's sperm. Egg collection and their storage should be handled similarly (see Thorsen et al., 2003). To ensure a female has eggs of good quality, a subsample of the stripped eggs should be placed into a beaker containing seawater to check for strong positive buoyancy (Kjørsvik et al., 1990) (particularly for fish species that spawn non-adhesive eggs). Eggs should be discarded if they were not easily expressed from the female or do not float to the incubator's surface. Eggs should be viewed under a stereomicroscope to evaluate whether they have a clear cytoplasm or a dark opaque contorted center. If a sample contains a high abundance of the latter, the female's eggs should be discarded, since these irregular oocytes cannot be fertilized (Kjørsvik et al., 1990; Thorsen et al., 2003). Eggs of moderate quality could be used if this is the intent of the experiment, for example, to examine male fertilization success in relation to egg quality. Controls should be conducted to examine for possible declines in egg quality over the experiment. To compensate for changes in gamete quality, replicates of different crosses could be conducted at random over the experimental period.

\section{b) Experimental design- semen dilutions}

The objectives of the experiment need to be clearly defined and the appropriate statistical analyses planned. To examine the fertilization capacity of males of different reproductive history (for example, firsttime $v s$ repeat-spawners), an appropriate number of males of each type need to have their sperm extracted and stored (Trippel and Neilson, 1992). The limited time allotted to conduct experimental crosses often influences the number of fish used. Each male should be replicated five times at minimum, as considerable variability often exists and the quality of one sample of embryos might deteriorate or be destroyed due to an experimental mishap. More replicates often decrease the within-male variance component of statistical analyses and provide greater ability to detect inter-male differences (for example, among 10 males ranging in condition). Availability of eggs can however limit the number of replicates possible. 


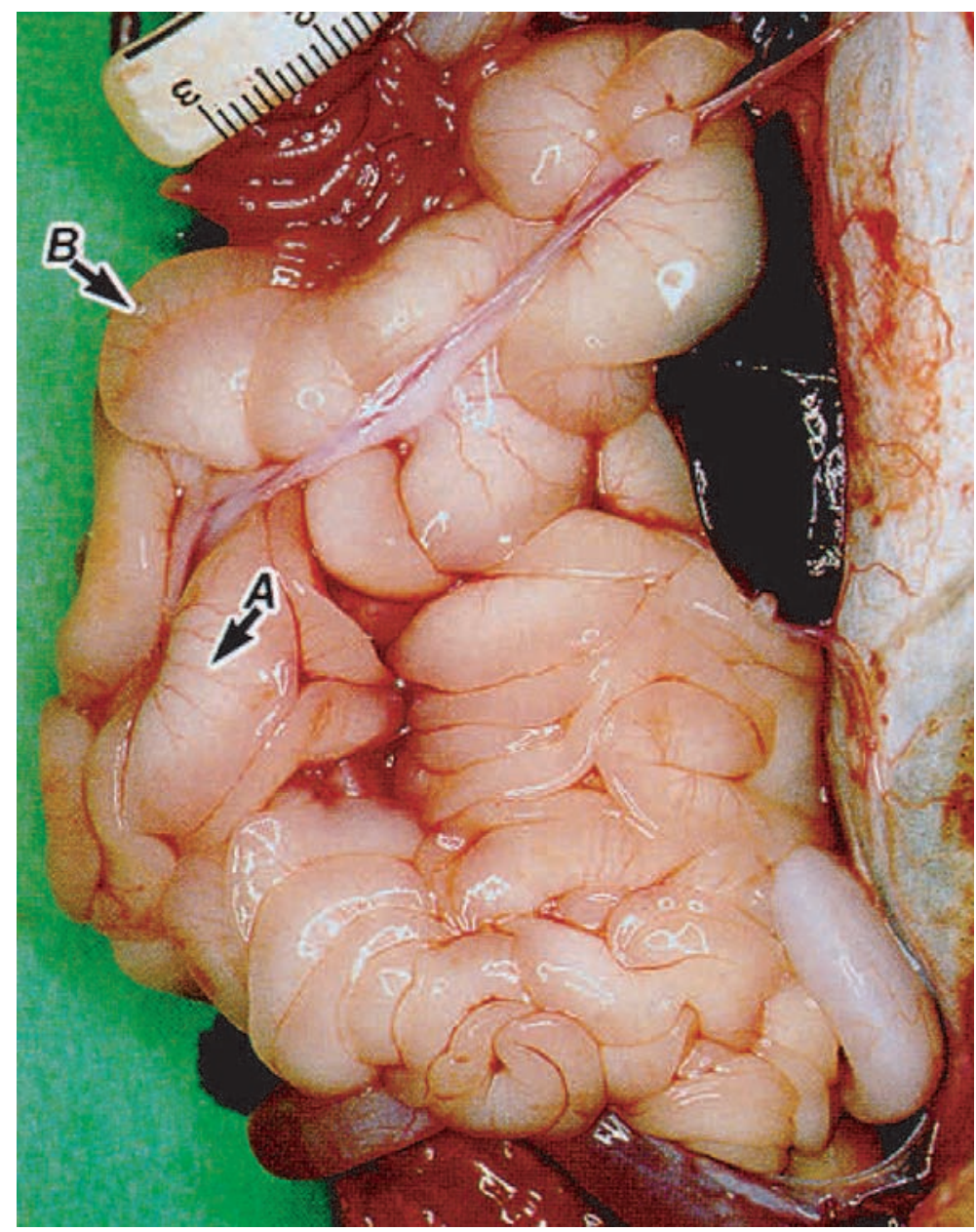

Fig. 2. Photograph of ripe testes of an adult Atlantic cod (Gadus morhua) (A) blood vessel in membrane of testis; (B) translucent border at distal edge). Source: Histology of the Atlantic Cod, Gadus morhua: An Atlas - Fisheries and Oceans Canada, 1990. Reproduced with permission of the Minister of Public Works and Government Services of Canada, 2003.

Semen:seawater dilutions used to examine sperm fertilization capacity have spanned from 1:1 to 1:1000 for studies on Northwest Atlantic cod, of which 1:500 and 1:1000 were the most suitable (Trippel and Neilson, 1992). Dilutions of 1:250 or denser led to $>80 \%$ fertilization success, yielding little among-male variability. Similar difficulty in achieving a broad range of fertilization rates was experienced in experiments with Atlantic herring (Clupea harengus) (Geffen, 1999) and Atlantic halibut (Hippoglossus hippoglossus $)\left(9.4 \times 10^{5}-4.6 \times 10^{8}\right.$ spermatozoa/ egg, Tvedt et al., 2001). Using very high dilutions, for example, $>1: 1000$ for cod, may generate very low fertilization rates or many zero values, also making among-male comparisons problematic. Hence, the number of spermatozoa per egg to be used in fertilization experiments is related to species and previous trials.

The study design chosen to estimate sperm fertilization potential does not have to be confined to one dilution but, based on gamete supply, can be extended to test sperm fertilization potential over a range of dilutions or sperm concentrations (Trippel and Neilson, 1992). Once the experimental design is finalized, a consistent method of introducing sperm, mixing it with eggs, and removing excess sperm should be adopted. The entire experiment should be conducted in a controlled temperature room. A good method of extracting sperm from the main holding 

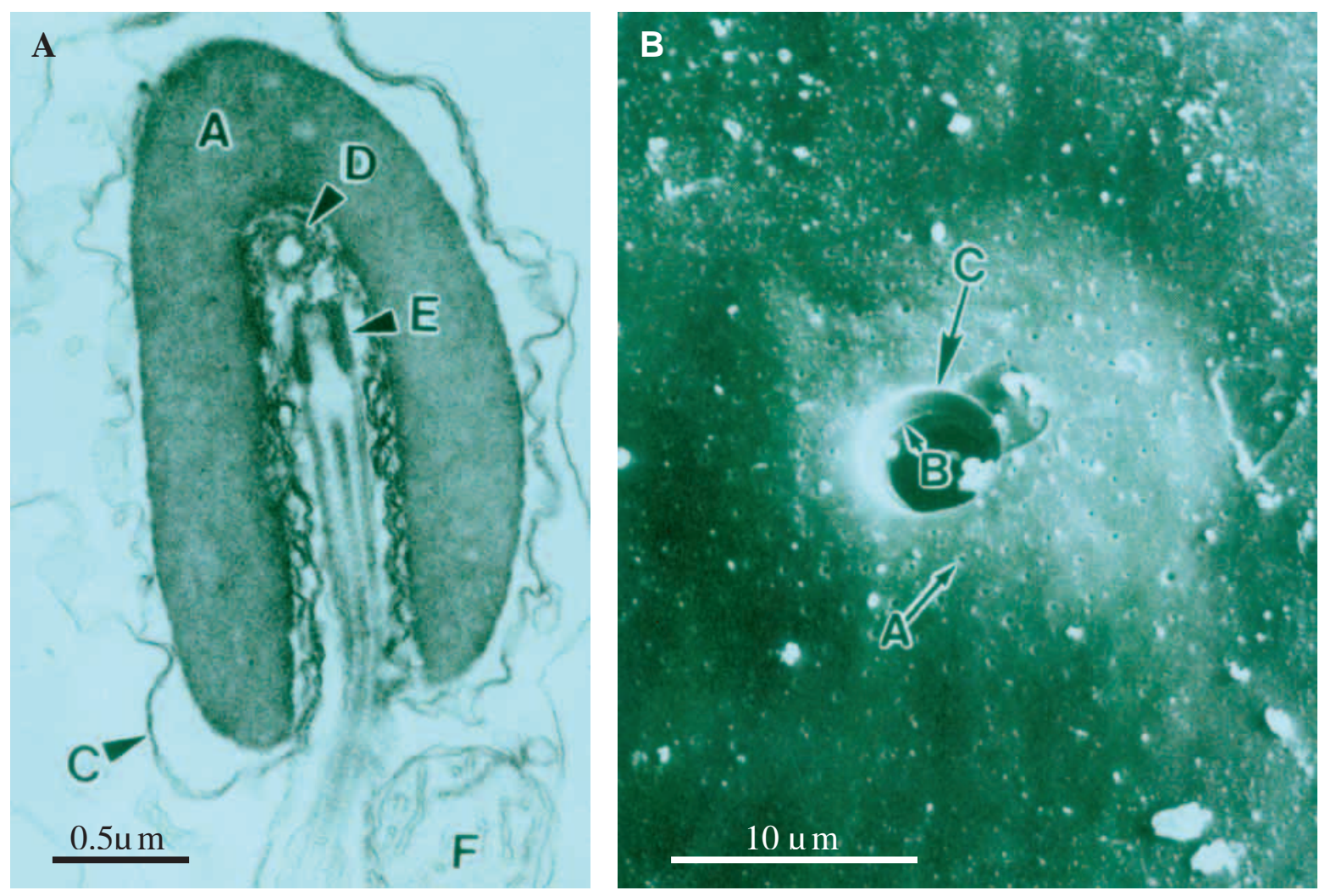

Fig. 3. (A) Photograph of head of sperm cell of Atlantic cod (longitudinal section). A: nucleus, C: nuclear membrane, D: proximal centriole, E: distal centriole, and F: mitochondrion. (B) Photograph of micropyle of an Atlantic cod egg. A: pore on mound, B: ridge of inner surface of micropyle, and C: rim of micropyle. (Source: Histology of the Atlantic Cod, Gadus morhua: An Atlas - Fisheries and Oceans Canada, 1990. Reproduced with permission of the Minister of Public Works and Government Services of Canada, 2003.)

beaker is to use a $100-1000 \mu 1( \pm 1 \mu 1)$ automatic micropipette (in which volume is digitally controlled). The tip aperture of a disposable plastic pipette can be enlarged by cutting off a portion which facilitates the entry of viscous semen. Five $250 \mathrm{ml}$ beakers, or other appropriate sized vessels, containing a predetermined volume of seawater of the desired temperature should be set up for each male. A pre-established volume of semen to attain the semen:seawater dilution is dispensed into a beaker (e.g., 1:500 dilution $=500$ $\mu 1$ semen in $250 \mathrm{ml}$ seawater) and the contents stirred with a glass rod for a brief fixed duration (e.g., six revolutions $(\sim 3 \mathrm{sec}))$. Eggs $(\sim 250-350)$ should be immediately added using a larger micropipette (1000$5000 \mu 1, \pm 10 \mu 1$ ) with the volume pre-calculated for each female depending on egg diameter. This mixture of eggs, semen and water is then gently swirled $(\sim 5$ sec) and allowed to stand for $1 \mathrm{~min}$. The sperm solution is then drained off, with care taken not to damage the sensitive eggs. Fresh filtered $(0.2 \mu \mathrm{m})$,
UV-sterilized seawater of the appropriate salinity and temperature is then added to the beaker (or the eggs are transferred into a new beaker containing fresh seawater). The process is repeated independently for each test sample. Some species, populations, and often certain individuals may have very sensitive eggs. Should this be the case, resting them on a nylon mesh (e.g., mesh size 1-mm square or less), as the water in the beaker is exchanged, can rupture their chorion. Because of these restricting circumstances, it is wise to conduct preliminary experiments to develop appropriate techniques that can be successfully deployed for a particular species or population when conducting a planned experiment (e.g., Marconato et al., 1997). A rapid and consistent method of removing eggs from the original test dilution is necessary (unless one wants to incorporate extended fertilizations and longer sperm:egg interaction times into the design). Unfortunately, some handling and artificial conditions will occur. As long as these are maintained constant, 
among treatment inter-male comparisons should remain valid. Exploration of the two-step dilution procedure used in the estimation of sperm density (e.g., Shangguan and Crim, 1999) is also worth pursuing when preparing diluted semen mixtures for egg fertilization trials.

Time to first cell division is species and water temperature dependent and normally occurs within $12 \mathrm{hr}$ after fertilization (Fridereisson, 1978; Kjørsvik and Lønning, 1983), making it feasible to evaluate fertilization success the next day. Eggs should be strained from each $250 \mathrm{ml}$ beaker and gently placed in a small Petrie dish. A video recorder or digital camera attached to a stereomicroscope (magnification 25-40×) should be used to facilitate recording of, for example, 100 samples of $250-350$ eggs each (i.e., if the study involved 20 crosses each with 5 replicates). Fertilization success can be determined from the recorded images at a later date. When estimating fertilization success it is important to exclude irregular eggs (i.e., deformed, enlarged, or those that are not clear). These eggs could be malformed or be under or over-ripe and are inappropriate to include when appraising sperm viability (Nissling et al., 1998). Commonly, eggs with 2-4 cells or more are considered fertilized as opposed to activated, i.e., eggs with one germinal cell but without cell cleavage (Howell et al., 1991) and eggs without cells (Nissling and Westin, 1997). Each male's ability to fertilize a female's eggs is represented by the average of the replicates.

If hatching success is of further interest, the eggs following videotaping could be returned to the 250 $\mathrm{ml}$ beakers for subsequent incubation to hatch $(\sim 15-$ 20 days and is a function of species and water temperature) (see Thorsen et al. (2003) for recommended techniques to incubate marine fish eggs). For Northwest Atlantic cod, handling in this way did not result in egg mortalities (Trippel and Neilson, 1992; Trippel and Morgan, 1994a). Other experimental options would have to be developed in cases where losses due to handling stress are significant. Note, in place of beakers, 11 hatching cones with flow through water could be used for egg incubation as dead eggs that settle to the bottom could be drained without disturbing the suspended viable eggs. Flow-through systems are more expensive and some loss of flexibility occurs when they are adopted. For example, if a larger experiment is developed there may not be enough hatching cones to accommodate all crosses and replicates. Additional beakers are simpler to purchase and set up. Hatching success also has been monitored of individual eggs placed in $1 \mathrm{ml}$ cells in small plastic plates (Panini et al., 2001; Thorsen et al., 2003). This avoids contamination among eggs and introduces statistical advantages as well as some disadvantages (e.g., inability to rear large numbers of larvae).

Atlantic halibut egg incubation requires elevated salinity to maintain eggs in the water column. Incubators commonly are 2501 (Terjesen et al., 1998) and incubation of individual eggs for lengthy periods in small cells is not possible. Herring have adhesive eggs, and their fertilization is conducted by gently spreading them onto glass plates (Blaxter and Hempel, 1963). The glass plates are then submerged in seawater containing the appropriate sperm density for a set period (e.g., $30 \mathrm{~min}$ ), removed, and then incubated in a tank containing fresh seawater (Rosenthal et al., 1988; Geffen, 1999).

\section{Sperm Density}

Male fertilization potential is dependent on semen quality or, more specifically, sperm number per unit volume of semen (density) and sperm motility. Sperm density and motility can be examined separately to evaluate their relative contribution to fertilization potential.

Individual males in a population vary in sperm density (Trippel and Morgan, 1994a). In fertilization trials these inter-male differences can be maintained if one uses the same semen dilution for each male (e.g., 1:500). However, if one wants to achieve equal sperm density among males in a fertilization trial (thereby facilitating the comparison of individual sperm cell performance) then the sperm density (i.e., number per $\mathrm{ml}$ of semen) of each male should be measured and the volume of semen used in crosses adjusted accordingly. Thus, sperm density estimates are meaningful in fertilization trials in which it is important to quantify the number of sperm per egg. Sperm density in conjunction with ejaculate volume is also used to estimate total sperm production by an individual during a spawning event or for the entire spawning season if spawning events are summed.

Two techniques are commonly used to measure sperm density: (i) spermatocrit and (ii) sperm counts of diluted semen sub-samples of known volume. Spermatocrit is a measure of the proportion of semen occupied by packed sperm cells in microhaematocrit tubes (75 mm length, 1.1-1.2 $\mathrm{mm}$ internal diameter) after high speed centrifuging (10 $\mathrm{min}$ at $7500 \mathrm{rpm})$ (Bouck and Jacobson, 1976) (Fig. 4). Two spermatocrit samples should be completed per male, and if they 
differ by $>10 \%$, a third sample should be done. Experience has shown that replicate samples are often within $2-3 \%$ of each other.

In cod, sperm density has been estimated by counting the number of sperm cells in a modified Neubauer haemacytometer and then as a proportion by estimating the number per ml. For example, Rakitin et al. (1999a) diluted seawater 500-fold and counted cod spermatozoa in $0.02 \mu 1$ aliquots $(n=3)$ at $400 \times$ magnification. These investigators showed, however, that haemacytometer derived estimates of cod sperm density correlated poorly with spermatocrit. A Coulter Multisizer particle analyzer (Coulter Electronics) has also been used to measure cod sperm density (Rakitin et al., 1999a). This technique was superior to haemacytometer counts. Dilutions were greater $(5 \times$ $10^{5}$-fold), spermatozoa were counted in $1 \mathrm{ml}$ aliquots, and lower variation among replicates was achieved (Rakitin et al., 1999a). The relationship between cod spermatocrit and sperm density (Coulter Multisizer) was $r^{2}=0.75$, whereas using a haemacytometer it was $r^{2}=0.13$. The better fit could be due to the large volume of dilution per sample of semen analyzed using a Coulter Multisizer. The small scale heterogeneity in the diluted mixture probably did not influence the accuracy of density estimates made with a Coulter Multisizer as it might have with a haemacytometer.

Spectrophotometry has been used to successfully estimate sperm density of turbot (Scophthalmus maximus) (Suquet et al., 1992a) and of several freshwater fish species (Ciereszko and Dabrowski, 1993). For turbot, a Malassez's cell was used to estimate sperm density after a 10 min decantation time and, although useful, proved very time consuming (2 hr per individual fish) (Suquet et al., 1992a). Though not encountered in cod, problems occurred for turbot in obtaining a significant spermatocritsperm density relationship (Suquet et al., 1992a). The authors consequently relied solely on spectrophotometry to derive sperm density estimates for this species. However, a significant positive relationship was reported between halibut sperm density and spermatocrit (Tvedt et al., 2001). Differences among studies may be related to the ability to achieve homogeneity in diluted sperm concentrations. A twostep dilution procedure has proven to be useful in the estimation of sperm density of winter flounder (Pseudopleuronectes americanus) (Shangguan and Crim, 1999) and yellowtail flounder (Liminanda ferruginea) (Clearwater and Crim, 1998). Further exploration of the two-step dilution procedure is recommended.

\section{Sperm Motility}

A numerical scale has been commonly used to assess sperm motility. For example, $0=$ non motile, $1=<5 \%$ motile, $2=5-29 \%$ motile, $3=30-79 \%$ motile, $4=79-95 \%$ motile and $5=>95 \%$ of sperm motile in a sample. Further distinction of the nonmotile category is occasionally made; vibrating (but not exhibiting forward motion) and those that are completely motionless (e.g., Westin and Nissling, 1991). Westin and Nissling (1991) also measured the duration (in min) of each phase (i.e., moving fast, moving slow, vibrating or no activity). These categories permit a viewer to rapidly score a sample of freshly diluted semen. Videotaping images of swimming sperm, on the other hand, provides a permanent record that can be evaluated subsequently and by other viewers. Sperm velocity $(\mu \mathrm{m} / \mathrm{s})$ from taped images can be estimated by measuring distance travelled by individual sperm cells (i.e., measuring distance travelled in a certain time (Billard and Cosson, 1992; Trippel and Neilson, 1992). Approximately 100 spermatozoa should be tracked per sample and it is a time-consuming process. Computerassisted sperm analysis (CASA) to assess the effects of pollutants on fish sperm has been successfully employed to estimate sperm swimming speed (Toth et al., 1995). This device automatically assesses speeds of high numbers of sperm and provides a digital data output (Kime et al., 1996). High-speed videomicroscopy has been used to study the flagella-beating frequency of fish spermatozoa (Cosson et al., 1997).

Longevity is another vital sperm characteristic (Fig. 5). Many marine fish species have lengthy periods of sperm motility lasting several minutes (Suquet et al., 1992a; Trippel and Morgan, 1994b; Geffen, 1999; Ciereszko et al., 2000) with activation of individual spermatozoa perhaps being staggered over time (Geffen, 1999). Sperm longevity can be evaluated by periodically sampling a semen:seawater mixture and measuring sperm motility for $1 \mathrm{~min}$. The interval between sampling is flexible given the limitations of labour and equipment. For some species, taping motility can be done every 10 min given that spermatozoa may still be active after $1 \mathrm{hr}$ (Trippel and Morgan, 1994b).

\section{Sample preparation}

Semen sampled for motility estimates should be used within 6-8 hr after stripping. Even though fertilization capacity continues for sperm stored on ice or in chilled oxygen filled syringes for much longer (24-48 hr, Billard, 1981), it is desirable to assess 

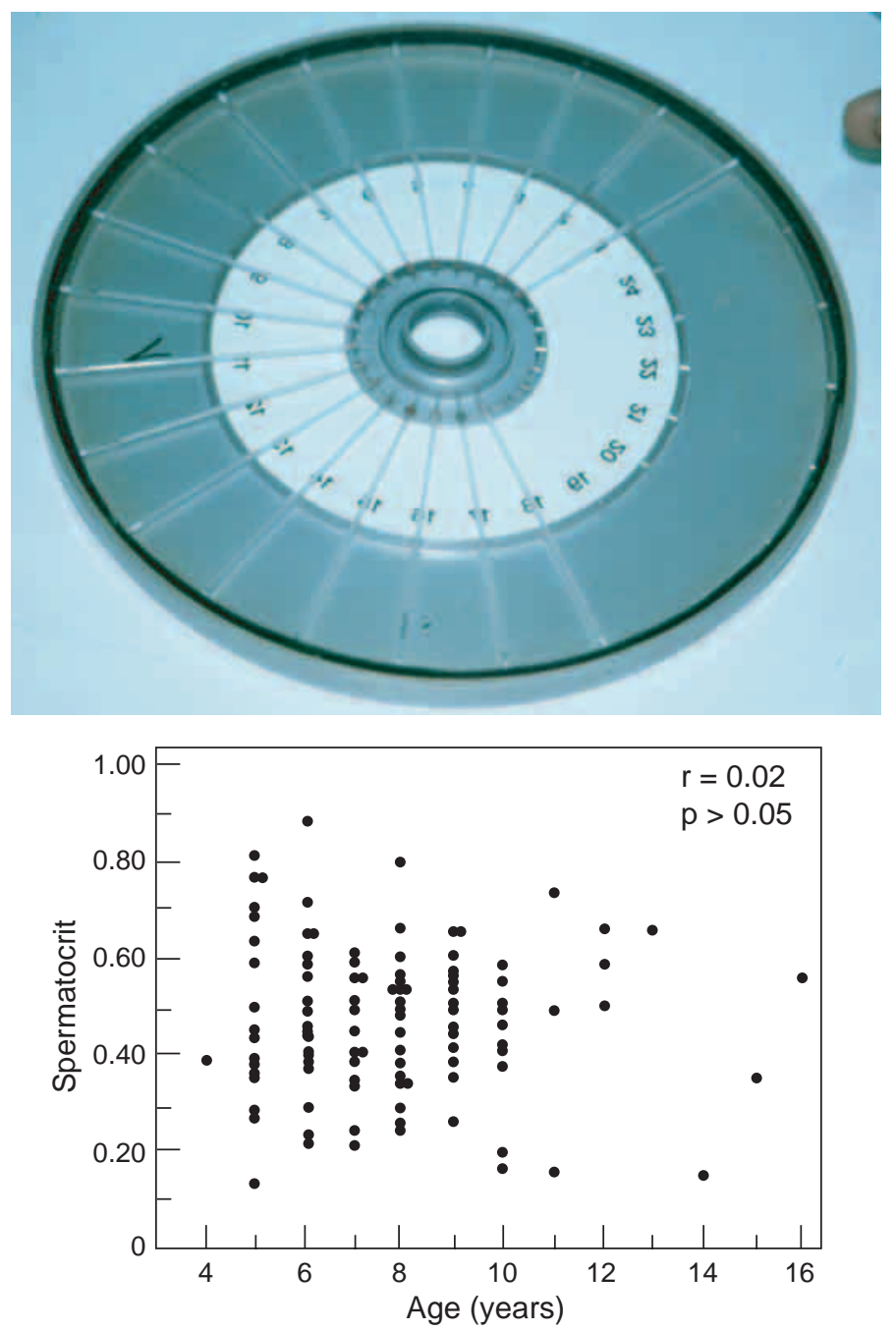

Fig. 4. Photograph of microhaematocrit tubes filled with semen being loaded into a centrifuge plate. Relationship between spermatocrit and age of Grand Bank cod collected in 1991. (Reproduced from Trippel, E .A., and M. J. Morgan. 1994. Age-specific paternal influences on reproductive success of Atlantic cod (Gadus morhua) of the Grand Banks, Newfoundland. ICES Mar. Sci. Symp., 198: 414-422. Copyright 1994, with permission from International Council of the Exploration of the Sea.)

motility of fresh sperm which more closely represent natural spawnings (Billard et al., 1993). If possible, controls should be carried out at the beginning, middle and end of the trials to assess whether storage time introduces a negative bias in the results. Sperm motility should be assessed of milt stored at the desired temperature and void of urine and water. In special cases where it is desirable to use a urine contaminated sample it might be possible to remove the urine with a pipette (because urine and milt remain as two separate phases) (Rakitin et al., 1999a), though urine is rather difficult to remove from semen in most instances. Semen has also been extracted from the testes of dissected fish without any deleterious effects on sperm performance compared to stripped sperm (Billard et al., 1997; Lahnsteiner et al., 1998).

It is recommended that motility assessments be conducted in a controlled temperature room. Alternatively, a compound microscope fitted with a 


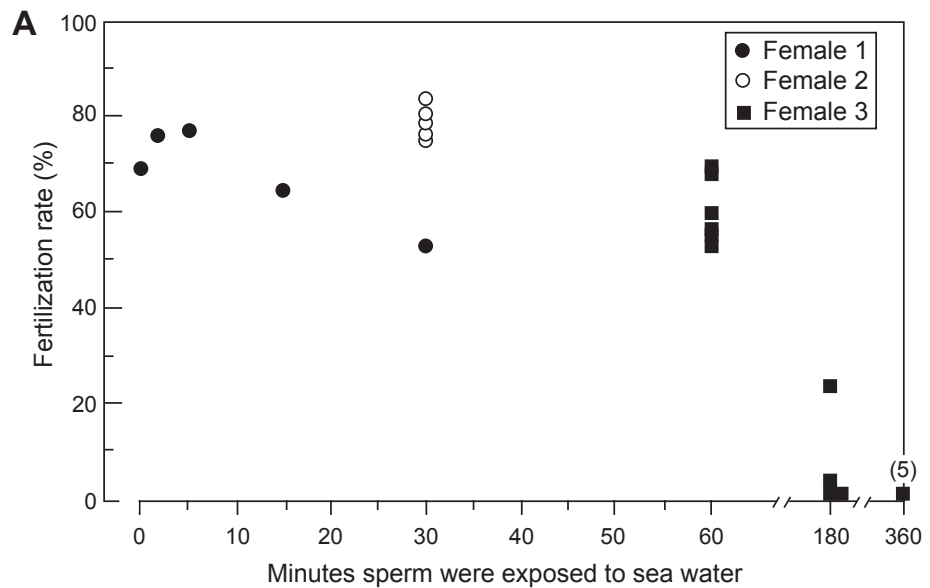

B
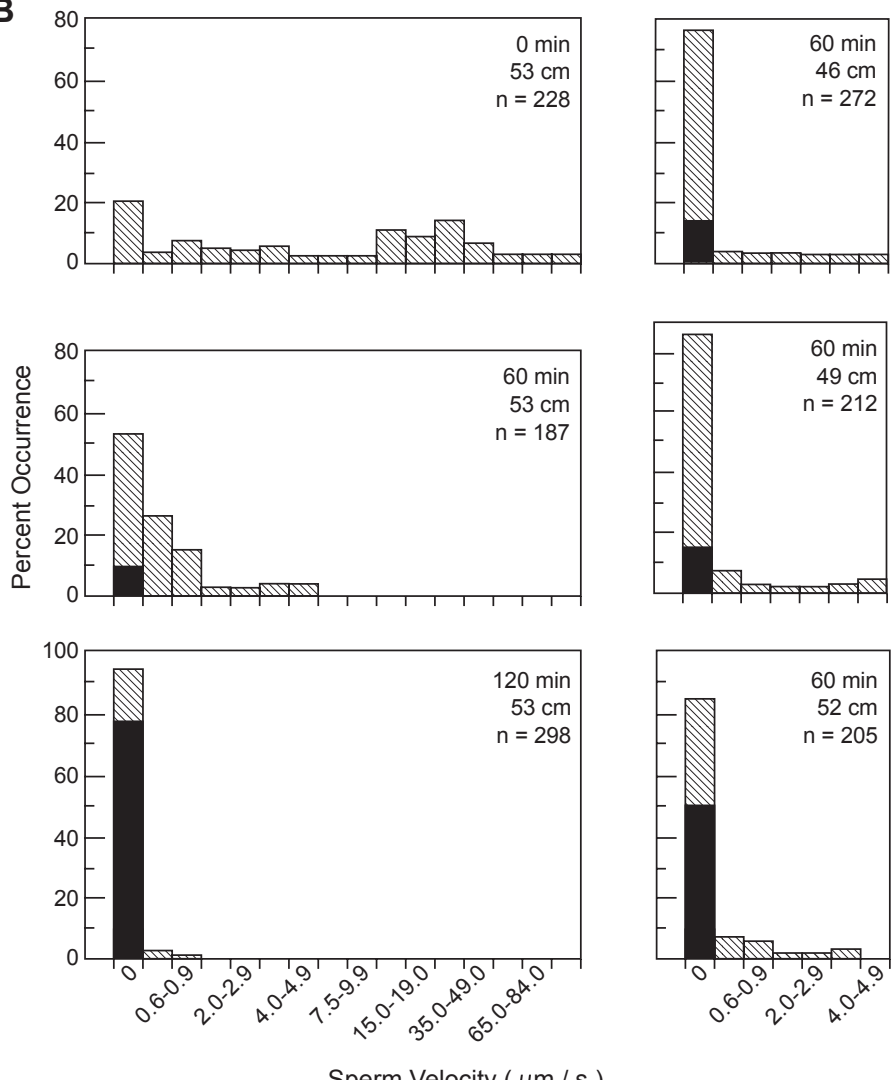

Fig. 5. (A) Relationship between fertilization rate and time sperm have been previously exposed to seawater for Atlantic cod. Female 1: $75 \mathrm{~cm}$ crossed with a male $67 \mathrm{~cm}$ repeated in triplicate at each time period (mean of three values shown); Female 2: $50 \mathrm{~cm}$ crossed with five males 61-67 $\mathrm{cm}$; Female 3: $52 \mathrm{~cm}$ crossed with nine males 48-67 cm. (B) Percent occurrences of Atlantic cod sperm having different swimming velocities at seawater exposure periods of 0,60 and $120 \mathrm{~min}$. The darkened bars represent sperm which were immotile, nonvibrating, and the crosshatched bars represent immotile vibrating and motile sperm. $\mathrm{n}=$ number of sperm. (Reproduced from Trippel, E. A. and M. J. Morgan. 1994. Sperm longevity in Atlantic cod (Gadus morhua). Copeia, 1994: 10251029. Copyright 1994, with permission from the American Society of Ichthyologists and Herpetologists.) 
stage-cooling device could be used, though one should be cautious of the effects of air temperature above the sample. Commonly a 1:250 semen:seawater dilution has been used to assess motility of cod sperm, where spermatocrit ranges from 30-70, although a lower dilution (e.g., 1:100) may also be used (Trippel and Neilson, 1992). It is advisable that the same dilution be applied to all males in the study, since level of dilution has been shown to influence duration of sperm motility in turbot (e.g., 1:10 vs 1:1000; Suquet et al., 1992a). Confusing high density sperm recordings should be avoided and could indicate the need for thinner dilutions (especially if measuring swimming speed of individual sperm cells). Long sperm tails could interfere with each other at high densities, reducing individual sperm velocity (this phenomenom may actually occur during egg fertilization). Detailed description of polyspermy and entry through an egg's micropyle are given elsewhere (Ginsburg, 1968; Amanze and Iyengar, 1990).

To prepare a sample for assessment of cod sperm motility, a pre-determined volume of semen is placed by micropipette into a beaker with known water volume to achieve the desired dilution (i.e., 1:250 dilution $=200 \mu 1$ in $50 \mathrm{ml}$ water $)$ and the sample is stirred with a glass rod $(\sim 3 \mathrm{sec})$. The tip of the glass rod is then used to place a drop on the haemacytometer, a glass cover slip is placed over the drop, and the sperm are quickly brought into focus at the desired magnification (e.g., 250-400×). It has been shown to take 20-30 sec to complete these steps from initial activation of sperm in water to focus. The sperm are then videotaped for $1 \mathrm{~min}$. The process is then repeated in at least triplicate, each sample being derived from its own dilution. In turbot, sperm motility has been estimated using dark field microscopy and stroboscopic illumination conducted with video recording. A two-step dilution process has been adopted with a final dilution of 1:1000 as fish semen is often viscous and difficult to mix with a dilutent (Chauvaud et al., 1995). The two-step dilution procedure has also been used on winter flounder (Clearwater and Crim, 1998), though it was first proposed by Billard and Cosson (1992) for rainbow trout in order to trigger a synchronous movement of $100 \%$ spermatozoa and to easily observe a small quantity of cells. Sperm motility of Atlantic halibut was estimated by Tvedt et al. (2001) by diluting $10 \mu \mathrm{l}$ of milt in $1 \mathrm{ml}$ of non-activating solution, and then 1 $\mu \mathrm{l}$ of this diluted solution was pipetted onto a microscope slide. Activation was achieved by adding $25 \mu \mathrm{l}$ of seawater and a qualitative score to sperm motility assigned. Once diluted, milt was held on ice in a cooler between preparation of slides. Other investigators of sperm motility have reported sample preparation periods to post-activation of $0 \mathrm{sec}$ (dilution prepared on microscope's stage) (Vladic and Jaervi, 1997) and $15 \mathrm{sec}$ (Toth et al., 1995). It is important to maintain consistency in post-activation times among samples. For turbot sperm, in order to obtain a 1:1000 two-step dilution Chauvaud et al. (1995) mixed $0.5 \mu \mathrm{l}$ of semen with $49.5 \mu \mathrm{l}$ non-activating medium. Then $10 \mu \mathrm{l}$ of this mixture were immediately diluted into $90 \mu \mathrm{l}$ of salt water. This process permitted the evaluation of motile and non-motile sperm within a few seconds after activation.

The process of conducting sperm motility experiments is not always simple. The use of a cover slip assists with the generation of a thin layer of sperm across the haemacytometer. The cover slip also prevents the occular from making direct contact with the sperm during magnification. It is also possible to use the edge of a glass cover slip to create a smear or thin layer across an unmarked glass slide (i.e., no underlying grid) and qualitatively score the sample. When focusing, it sometimes becomes apparent that more than one layer of sperm exists on the slide (e.g., cod sperm head length $\sim 5 \mu \mathrm{m}$ ) (Fig. 3A). Allowing time for decantation of sperm would result in a single layer of cells, but this delay would introduce a negative bias on sperm motility estimates and is not recommended. It is important to remain focused on a single plane during videotaping. Occasionally unidirectional flowing of sperm occurs through the field of view and is easily recognized (created by movement of the solution), making sperm motility estimates problematic. Care should be taken to avoid these samples. If this is not possible, a frame of reference should be used to estimate self-propelled motility. Clean dry glassware should always be used for each sample to avoid contamination by other sperm and water. A frame counter (video timer, $\pm 0.01 \mathrm{sec}$ ) should be used to denote which tape segments refer to each sample. Samples from various males should be performed randomly to avoid the possible effect of milt ageing on motility (Ciereszko et al., 2000).

\section{Paternal Effects on Reproductive Output in Paired Mating}

Considerable effort has been made in recent years to measure maternal factors affecting fecundity, egg size and fertilization success of gadoids that spawn freely in captivity (Hislop et al., 1978; Kjesbu et al., 1996; Trippel, 1998; Thorsen et al., 2003). Paternal 
factors may have partly influenced the results of these experiments (especially related to fertilization). Further investigation of male effects in free spawning adult pairs is warranted to appropriately gauge results derived from maternal-based experimental designs. The following describes guidelines that tend to minimize introduced male effects in paired mating studies.

\section{Broodstock collection and husbandry}

Knowledge gathered on fecundity and egg viability from captive adult pairs has been critical to the estimation of reproductive potential of natural populations. Further research in this area should be conducted using fish collected as juveniles using handlines or trawls, rather than using fish cultivated from eggs (see Thorsen et al., 2003). Their diet while in captivity should be similar to the wild, i.e., in the case of Northwest Atlantic cod, a diet of herring, capelin (Mallotus mallotus), squid (Ilex sp.) and shrimp (Pandalus sp.). Prepared dry and moist pellet diets that require less labour are also options, though they are more removed from their natural diet, and due to a relatively high fat content, lead to enlarged livers (Nanton et al., 2001; Lambert and Thorsen, 2003). Fish should be tagged (external or internal) to maintain record of their growth and reproductive history while in captivity. Mixed sex conditions should be maintained in large holding tanks during the nonspawning period to accommodate the positive maternal effect on sperm motility (Suquet et al., 1992b). Distribution of adult pairs to smaller spawning tanks is dependent on the experimental design and commonly occurs 2-3 weeks prior to the onset of spawning (Fordham and Trippel, 1999). Fish should be anaesthetized and initial length and body weight recorded and milt expressed to verify sex and gauge sexual readiness. Ultrasound has also been proven to be a useful non-lethal tool to determine sex and ripeness (Martin-Robichaud and Rommens, 2001). A few days after transfer to spawning tanks, fish should be free of symptoms of fright or stress (such as dark skin blotches) or immobility (Billard et al., 1981). Plasma cortisol levels may be measured to assess stress level (Barton and Iwama, 1991; McCormick, 1998; Morgan et al., 1999). Sound production by gadoids during courtship is caused by rapid contraction and relaxation of the drumming muscles attached to the swimbladder (Templeman and Hodder, 1958; Brawn, $1961 \mathrm{a}, \mathrm{b}$; Hawkins and Rasmussen, 1978; Hawkins and Amorim, 2000) and the absence of these sounds can help to evaluate whether a male is stressed. Sound production of individual male haddock (Melanogrammus aeglefinus) occurs throughout the spawning period (day and night), even when isolated with a female and no other male is present (Bremner et al., 2002). When monitoring egg production of a female, the accompanying male should be within $10 \%$ of the maternal length, as size of male relative to female may influence mating success (Rakitin et al., 2001; Bekkevold et al., 2002). There may be a number of factors responsible for the failure of eggs to be fertilized during the lengthy spawning period of a female ( $\sim 30-40$ days). In the case of the male, one could examine for the presence of swimming activity. Males normally exhibit greater swimming activity than females and often circle the tank bottom (Hawkins and Amorim, 2000; Rakitin et al., 2001). If sound production ceases, it may be a sign that the male has completed annual spawning (Bremner et al., 2002). Removing the individual and checking for milt is another way of checking for cessation of spawning. However, the absence of milt may not be a true reflection of its remaining ripeness. Occasionally, milt is not readily expressed in this way, and the individual continues to mate when returned to the tank. Creating a spawning trio, two males and one female, could lead to additional male effects on the viability and characteristics of the progeny (i.e., beyond a single male) (Panagiotaki and Geffen 1992; Rakitin et al., 2001; Wedekind et al., 2001; Saillant et al., 2001). If 10 females are monitored in 10 tanks, they will each have a different sire, inevitably introducing some male effects into the results. Male selection and replacement therefore need to be carefully considered prior to the formation of spawning pairs.

For turbot, and many other pleuronectoids, individuals need to be manually stripped to conduct pair matings (Chereguini et al., 1999; Watanabe and Carroll, 2001). Because sperm volume collected from stripping is typically low in small flatfishes (oligospermy), a catheter is often used to take sperm from the genital pore (as noted for rainbow trout by Glogowski et al., 2000). Variable spawning success in flatfishes can be attributed in large part to inconsistent male performance and inadequate spermiation (Watanabe and Carroll, 2001). Hormone treatments have been used to stimulate spermiation and ovulation in pleuronectoids (Clearwater and Crim, 1998) and consequently gamete collection is more complicated than for gadoids. Culturists of summer flounder (Paralichthys dentatus) and southern flounder ( $P$. lethostigma) used a "light table" to estimate time of ovulation and used intramuscular implantation of a slow-release LHRHa pellet into females to induce repetitive ovulation and spawning 
(Watanabe and Carroll, 2001). In yellowtail flounder, GnRHa treatment did not have a negative effect on sperm fertilizing ability, percent hatch or larval morphology, and it positively influenced sperm production, milt volume and sperm motility (Clearwater and Crim, 1998). Additional consideration must be made of handling stress and the effects of stripping frequency on milt quantity and quality (Suquet et al., 1992b). Ability to coordinate time of stripping with ovulation in flatfish is important so that eggs do not become over-ripened or released freely in the holding tank (Devauchelle et al., 1988). Use of GnRHa implants lowered sperm density in Atlantic halibut (Tvedt et al., 2001), whereas hormonal treatments used to induce ovulation in female summer and southern flounder were ineffective in inducing spermiation (Watanabe and Carroll, 2001).

\section{Application of Genetic Markers to Sperm and Group Mate Competitions}

Species-specific genetic markers have become an important tool in the study of fish population dynamics and aquaculture (Jordan and Youngson, 1992; Bentzen et al., 1996; Herbinger et al., 1997; Wooninck, et al., 1998; O'Reilly et al., 2002). Molecular genetic markers used to assign parentage through ontogeny (parents, spawned eggs, advanced embryos and larvae) have broadened the type of research that can be conducted to assess paternal variability in fertilization success.

Male fertilization success - sperm competition. Without genetic analyses, one is confined to evaluating male effects by using milt of individual males to fertilize eggs of one or more females and incubating the family replicates separately. Genetic markers make it possible to simultaneously create and monitor progeny of several half-sibling crosses (sharing the same dam but having different sires). For example, a series of sire pairs could be chosen that differ as follows: (low vs high condition, virgin vs repeatspawning, small vs large body). Rakitin et al. (1999b) used sperm of 8 males of contrasting body length to create paired sperm competitions using eggs of three females and conducted 10 sets of matings (each in triplicate). Male condition correlated positively with fertilization success when the volume of semen was adjusted to add approximately equal numbers of spermatozoa from each male (Rakitin et al., 1999b). More than two males can also be used, for example along a gradient of length or condition factor (e.g., 10-20 males with one or more females). A number of sperm competition studies have been conducted in which genetic markers were used to reveal variation in performance among males (Gile and Ferguson, 1995; Babiak et al., 1998; Rakitin et al., 1999b). Males can potentially influence embryonic survivorship prior to hatch, and it is therefore important to sample zygotes through time. It is possible to isolate DNA from some species, such as Atlantic cod and haddock, as early as the 16- and 32-cell stages (J. A. Hutchings and P. T. O'Reilly, pers. comm.). The number of parental combinations detected in an egg batch as a function of a randomized number of genotyped offspring showed that a minimum of 20 embryos should be analysed to evaluate parentage (Bekkevold et al., 2002), however a greater number yields greater precision in estimates of relative sire potency.

Sperm density is a principal factor contributing to male fertilization success. Sperm density differences among males can be accounted for by measuring spermatocrit of the intended sires. If one sire has $25 \%$ thicker semen than the other, then $25 \%$ less semen of this sire should be added to the solution into which eggs are introduced. The final semen:seawater dilution would account for the differing quantities of milt of the two males (e.g., in a 1:500 dilution). This is referred to as the equal density approach and enables a fairer test of the quality or fertilization capacity of individual spermatozoa (Rakitin et al., 1999b). An equal volume approach does not account for inter-male differences in sperm densities as it uses the same amount of milt of each male. The equal volume approach better reflects the semen flowing from two males during spawning. However, many other "natural" factors have already been held constant in the experiment such as ejaculate volume and mating behaviour (Trippel et al., 1998). Both equal density and equal volume techniques are of interest, though if time and gametes are limited, the former is more significant in the evaluation of sperm quality. In addition to sperm competitions, fertilization success should be estimated using sperm of each male independently (Rakitin et al., 1999b). This will enable the independent detection of poor performing males.

Cryopreservation of semen has been established for a number of teleosts beginning primarily with salmonids (Scott and Baynes, 1980; Stoss, 1983; Rana, 1995; Glogowski et al., 1999). Despite the need for further cryopreservation research, the technology currently exists for long-term storage of male gametes of selected marine species (Mounib, 1978; Leung and Jamieson, 1991; Suquet et al., 2000; Ohta et al., 2001; Rideout et al., 2003). In turbot, no significant 
differences in fertilization rate, hatching rate, survival and wet weight of 10 day-old larvae were reported using fresh or frozen-thawed spermatozoa (Suquet et al., 1998). However, individual male variability was noted in cryopreservation of bream (Abramis brama) sperm (Glogowski et al., 1997). Long-term storage capacity could provide the opportunity to assemble sperm from parents of the specific characteristics desired for an experimental cross. For example, 10 first-time and 10 repeat-spawning males could be stripped and their gametes stored. It may also be possible to sample gametes by inducing adults to spermiate through gonadotropin hormone implants or injections (Garcia, 1991; Clearwater and Crim, 1998). Sperm competition experiments could then be conducted when a sufficiently large egg batch has been obtained of good quality (or when eggs of more than one female have been collected if maternal-paternal interactions are the aim of the study).

Analysis of "male effects" is not restricted to stripping males and conducting sperm competitions. For some species, it is also possible to sample freely spawned eggs in tanks in which two or more males are held with one female. Parentage of over $51 \mathrm{cod}$ spawning events of 8 trios ( 2 males and 1 female) revealed evidence of size-assortative mating of cod. Large males that were more than $25 \%$ of the length of the female had low seasonal reproductive success and only male cod with a body length within $13 \%$ of females fertilized entire egg batches (Rakitin et al., 2001). Additionally, a large majority of egg batches of all females had both males contributing to offspring paternity. This indicated that sire dominance was not achieved in the captive trios. Monitoring progeny from larger spawning groups of cod (e.g., 6-131 adults) has been used to examine communal mating behaviour and whether an alpha-male becomes established (Jørstad, 1986; Hutchings et al., 1999; Bekkevold et al., 2002). Behavioural observations and associated male sound production of haddock has also been studied in communal spawning tanks (Hawkins and Amorim, 2000). In Atlantic salmon (Salmo salar), male fertilization success was influenced by a variety of factors, including sperm precedence, male size, and spawning history with sperm limitation likely influencing individual success (Mjolnerod et al., 1998). Group spawns resulted in higher egg fertilization rates compared to mono-male spawns in bluehead wrasse (Thalassoma bifasciatum; Robertson, 1996), though no difference was noted for cod when one compared to two males were mated with a female (Rakitin et al., 2001). Size-dependent reproductive advantages existed in the Japanese medaka (Oryzias latipes) where females associated with large males and, when mate competition was strong, large males obtained almost every mating (Babiak et al., 1998).

\section{Paternal Effects on Hatching Success, Larval Traits and Early Life Survival}

The effects of male parent on egg hatchability is an infrequently studied aspect of marine fish early life history (Trippel and Neilson, 1992; Nagler and Cyr, 1997). Hatching success has been reported to range from $30-75 \%$ among half-sibling embryos in Atlantic cod, though the differences were unrelated to sire length and age (Trippel and Morgan, 1994a) (Fig. 6). Tests involving first-time and repeatspawning males have reported that mean hatching success was not related to years of reproductive experience, though first-time spawners exhibited a greater coefficient of variation in hatching rate (Trippel and Neilson, 1992). In herring, sperm motility correlated positively with larval length at hatch (Evans and Geffen, 1998) which is an interesting finding in the study of male-influenced early larval traits (Fig. 7). Sire breeding ornamentation was positively correlated with parasite resistance of embryos in Alpine whitefish (Coregonus sp.), such that strongly ornamented males sired offspring that better survived the epidemic during egg development (Wedekind et al., 2001). Paternal effects on early life history traits of haddock have also been recently demonstrated (Rideout et al., in press). Consequently, mixing sperm of different males to assess maternal effects should be avoided. These studies may have difficulty in accurately assessing among-female differences, due to potentially significant male effects and male-female interactions in the phenotypes, as reported for European sea bass (Dicentrarchus labrax) (Saillant et al., 2001).

Greater husbandry requirements are needed for studies on hatching compared to fertilization success. The period of study is longer ( $\sim 15-20$ days) and maintaining water quality is important. Husbandry should be conducted as described for experiments on maternal influences on egg hatching success (see Thorsen et al., 2003). Dilute sperm mixtures are not necessary to produce embryos for hatching experiments. Fertilized eggs can be created using concentrated sperm dilutions (e.g., dry fertilization) which potentially increases the number of fertilized eggs per sample.

The ability of a sire to shape larval characteristics and performance is of great interest (Panagiotaki and 

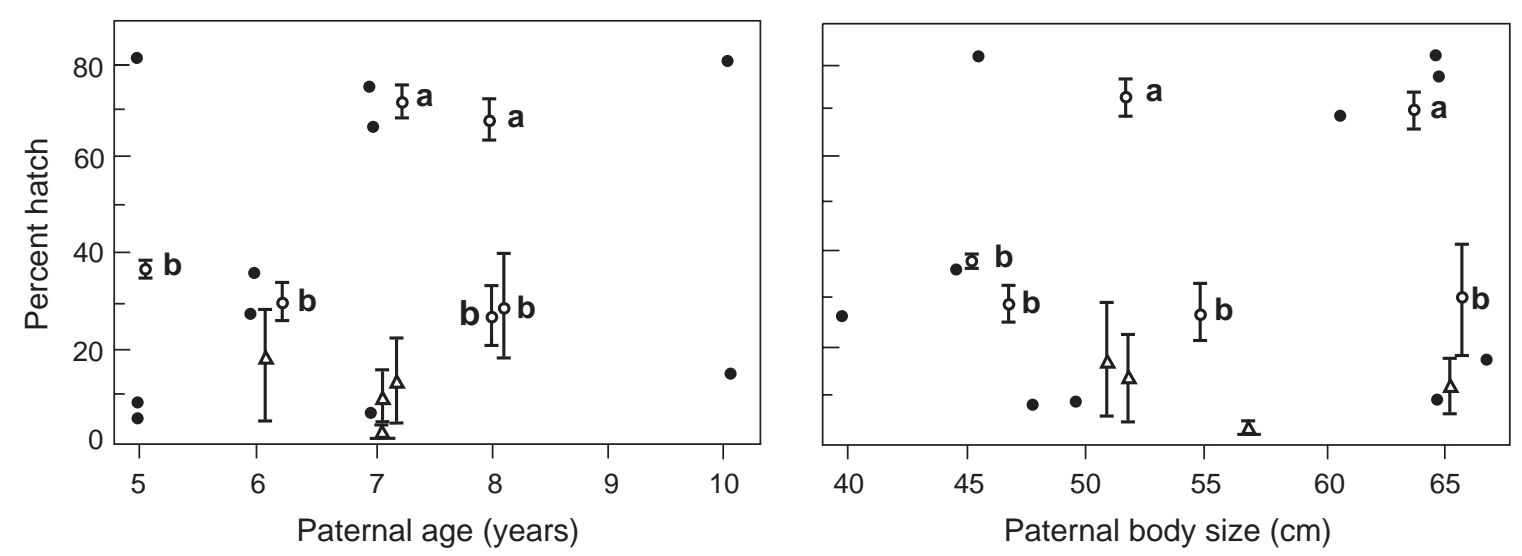

Fig. 6. Relationship between hatching success of Grand Banks cod eggs and paternal age and length. Each symbol refers to a different female $(n=3)$. Bars represent one standard error. Comparison of hatching success should be restricted to crosses using eggs of the same female (i.e., having the same symbol). For each symbol, values not having a common letter differ significantly. (Reproduced from Trippel, E. A., and M. J. Morgan. 1994. Age-specific paternal influences on reproductive success of Atlantic cod (Gadus morhua) of the Grand Banks, Newfoundland. ICES Mar. Sci. Symp., 198: 414-422. Copyright 1994, with permission from International Council of the Exploration of the Sea.)

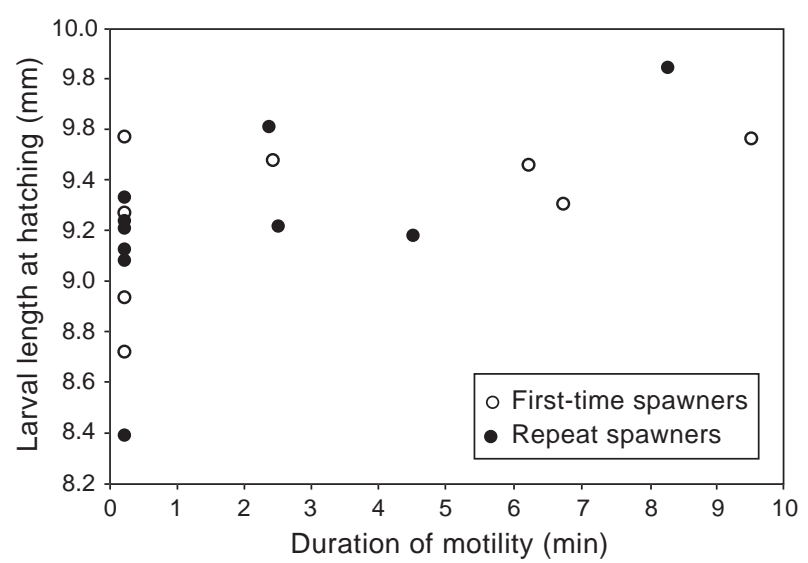

Fig.7. Relationship between larval length at hatch and sperm motility (duration) of Celtic Sea herring (firsttime spawners age 3 years, repeat-spawners ages $4-$ 7 years). For each male, hatching lengths represent the mean of 20 larvae. (Reproduced from Evans, J.P. and A.J. Geffen. 1998. Male characteristics, sperm traits, and reproductive success in winterspawning Celtic Sea Atlantic herring, Clupea harengus. Mar. Biol., 132: 179-186. Copyright 1998, with permission from Springer-Verlag GmbH \& Co.)

Geffen, 1992; Rideout et al., in press), as maternal effects are generally presumed to control this early life stage (Bengtson et al., 1987; Chambers et al., 1988; Chambers and Leggett, 1996). The male effect can be studied for several weeks or months as larvae continue to grow and commence exogenous feeding and become juveniles. Standardized experimental methods will be required during larviculture as many factors could possibly mask underlying male effects. Studies on size-dependent survivorship (Meekan and Fortier, 1996) and lipid class composition (Lochmann et al., 1995) of larval cod of the Scotian Shelf are of relevance. Continued examination of the male effect can be done using a large tank (e.g., 5000 l) where progeny of several sires and dams are pooled. This may minimize the "tank effect" problem common to following isolated families in small aquaria (e.g., 40 1). However, there still may exist some interactions between families and rearing conditions that influence survivorship differently according to origin of larvae. Pooled family rearing is costly due to necessary DNA analysis, and in itself should also be replicated, which is rarely done. Studies to monitor the growth and survival of larvae originating from specific families of pleuronectoids and gadoids are rare (e.g., Chambers and Leggett, 1992; Clemmesen et al., 2003). It is anticipated that greater gains in this area will occur as the development of aquaculture breeding programs for species of these taxa advance over the next ten years.

\section{Available Information on Male Reproductive Traits from Field Studies}

\section{Sex Ratio, Maturity, Stage of Spawning and Gonadosomatic Index}

Males are often assumed to represent $\sim 50 \%$ of a fish population. However, attempts to accurately 
estimate sex ratio in natural populations becomes problematic, since sexes are often partially segregated (both horizontally and vertically) and this shifts seasonally in conjunction with the spawning period (Morgan and Trippel, 1996; Tomkiewicz et al., MS 1997; Nordeide and Kjellsby, 1999; Jakobsen and Ajiad, 1999). Some sex ratios may not be maintained at 50:50 as a result of disproportional fishing effort that is associated with gender (Kosior and Skólsky, MS 1992; Brule et al., 1999). Females often begin to outgrow males shortly after attaining sexual maturity and old, large individuals of many fish species tend to be females (Roff 1982, Scott and Scott, 1988; Rijnsdorp and Ibelings, 1989; Trippel, 1995; Hunt, 1996; Burton and Flynn, 1998). Consequently, sizeselective harvesting practices as a result of mesh size could influence size- (and age-) specific sex ratios. Overfishing that reduces stocks to a few young cohorts is therefore likely to produce a shortage of adult females rather than males, as faster-growing females are more vulnerable to the size-selective gear. Sexselective exploitation, either directly on gender (Morgan and Trippel, 1996; Jakobsen and Ajiad, 1999) or indirectly through body size, is thus potentially widespread and the impact of the resulting skewed sex ratios should be considered in estimates of reproductive potential of fish populations.

The allocation of energy into male reproductive tissue (primarily sperm production) varies among species, populations, individuals and time (seasonally and annually) (Sorokin 1960; Iles 1964; Burton and Idler, 1984; Berner, 1985; Rijnsdorp, 1990; Tomkiewicz and Köster, MS 1999; Rideout and Burton, 2000). Given this variability, and that it may have some bearing on recruitment, it is noteworthy to establish procedures for measuring energetic investment in spermatogenesis. Distinction between immature and mature males within a population is of prime importance. Statistics collected from subsampled research survey catches often include data on gonadal stage of development (e.g., immature, developing, ripe, spawning, spent and resting stages). To facilitate stage identification, photographs of different gonadal stages of various body sizes of a species should be supplied to research survey personnel (e.g., Morrison, 1990; Tomkiewicz et al., 2002). Samples of testes may need to be returned to the laboratory for stage confirmation. For females, immature and resting stages cannot be accurately distinguished without histological analyses (Trippel et al., 1997a; Saborido-Rey and Junquera, 1998). Similar histological analyses may also be needed for testicular staging. In cod, spermatogenesis seems subject to delays in its initiation, with individuals within a stock showing considerable variation in stages attained (Burton et al., 1997). In male winter flounder, mitotic proliferation of reserve spermatogonia was completed six months before the onset of spawning (Moulton and Burton, 1999). Many marine species are determinate spawners including most gadoids and pleuronectoids and the amount of sperm present in the testes of ripe males represents the number of spermatozoa to be released during the spawning period (Rideout and Burton, 2000; Murua and Saborido-Rey, 2003). In addition to the utility of gonadal staging to distinguish immature from mature fish, staging can also be used to determine the extent of spawning season, particularly when a number of surveys occur within a year (Hutchings and Myers, 1993; Tomkiewicz and Köster, MS 1999).

The gonad weight of mature ripe males should be recorded (when confident they have not yet initiated sperm release) to provide a measure of the individual's annual allocation of energy to reproduction. The stage most suited for accurate representation of sperm production is when spermatozoa are fully mature, the testes are then enlarged, though significant hydration of the testes in preparation for spermiation has not been initiated (e.g., stage 4 in Trippel et al. (1997a) described as white and distended into wavy lobules and a small amount of milt may be forced out by pressure) (Fig. 2). Together with somatic weight, ripe gonad weight can be used to generate testes weightbody weight relationships. The development of annual mature testes weight-body weight relationships from research survey data would provide the basic capacity to estimate annual sperm production of different fish size-classes within a population (Rajasilta et al., 1997; Burton et al., 1997).

Spawning season according to sex and body size can be used to establish whether sperm limitation exists for gravid females of particular sizes, or in specific spawning areas of a stock. Seasonality of spawning may differ among age groups of fish, such that small males may begin to spawn earlier and end earlier than large males (Hutchings and Myers, 1993; Trippel and Morgan, 1994a; Trippel et al., 1997b). Moreover, if small precocious males (Fig. 1) persist in an unspawned state when other males have spawned out, this would provide evidence that they did not participate in mating and should be discounted in estimates of stock reproductive potential (Trippel and Morgan, 1994a). In smallmouth bass (Micropterus 
dolomieui), a freshwater nesting fish, $\sim 10-45 \%$ of young mature males (age 4-5 years) established nests which increased to $\sim 75 \%$ at older ages (Ridgway et al., 1991). Gonadal inspection also offers the ability to evaluate the extent of sperm atresia, either of the entire year's production or resorption of some remaining portion of mature spermatozoa left in the testes after cessation of the spawning season (e.g., Rideout et al., 2000).

Estimation of male stock biomass is possible by using routine stock assessment data once sex ratio and maturity ogives are applied to cohort abundance. For determinate spawners, stock "sperm production" could then be estimated from testes weight-body weight relationships developed for ripe fish in each year (Trippel, 1999). Condition factors (e.g., Fulton's condition factor; liver condition index) have been shown to be important proxies for reproductive investment in females (Lambert and Dutil, 1997b; Yaragina and Marshall, 2000; Lambert et al., 2003). Perhaps similar condition factors could be used for males to estimate mature testes weight, reducing the need to measure or have data available of testes weight in every year of a recruitment time series.

Obtaining estimates of spermatocrit, sperm motility and sperm fertilization potential are possible in field studies. However, other than spermatocrit, these male traits are more easily measured in the laboratory as described earlier.

\section{Viable Sperm Production of a Fish Stock}

While knowledge about male reproductive traits has been successfully applied in aquaculture for several decades, attempts to evaluate male reproductive potential in natural populations rarely exist. This section outlines the possible ways in which data on male reproductive traits can be applied to the estimation of viable sperm production of a fish stock.

\section{Application of Spermatocrit Data to Estimation of Stock Sperm Production}

Spermatocrit of cod varies annually as well as across age and size classes (Fig. 4; Trippel and Morgan, 1994a). This may reflect different nutritional or environmental conditions among years and could lead to fluctuations in the fertilization capacity of a population. Even though spermatocrit-sperm density equations have not yet been derived for many exploited marine fishes, routine measurement of spermatocrit of fish captured at sea could be initiated to provide scalar information on annual and seasonal variation in sperm density. In some species, spermatocrit tends to thicken as the spawning season progresses (Atlantic halibut, Methven and Crim, 1991; haddock, Trippel et al., 1998; and Atlantic cod, Rakitin et al., 1999a) and in other species spermatocrit declines seasonally (turbot, Suquet et al., 1992b; Baltic Sea herring (Clupea harengus membras), Rajasilta et al., 1997; and yellowtail flounder, Clearwater and Crim, 1998). Although spermatocrit has been shown to vary among individual Atlantic cod held in captivity, it tends to remain consistent (both absolute and seasonal patterns) for individuals in successive years, regardless of male age, body size and condition factor (Fig. 8) (Rakitin et al., 1999a).

In Northeast Arctic cod, variation in spermatocrit levels among males was associated with both mass of sound-producing drumming muscles and fin size (Engen and Folstad, 1999). In promiscuous guppies (Poecilia reticulata), level of sexual activity and display rates correlated positively with sperm number and males adopted mating strategies to suit their social environment (Matthews et al., 1997; Evans and Magurran, 1999). Consequently, variability in spermiation and in the seasonal quantity of spermatozoa produced per unit weight of testes are of relevance in the estimation of male reproductive potential.

\section{Application of Sperm Motility Data to Estimation of StockViable Sperm Production}

The usefulness of sperm motility estimates as a measure of male potency in fish has received relatively minor attention and requires further study. Westin and Nissling (1991) have examined the effects of salinity on sperm motility and egg fertilization success in Baltic cod. At very low salinities (11.5 and $12 \mathrm{ppt}$ ), sperm vibrated or were non-motile, yet at $12.5-30 \mathrm{ppt}$ and higher there occurred substantial sperm movement. Interestingly, 5-20\% of eggs were fertilized at 5 and $7 \mathrm{ppt}$ and $\sim 100 \%$ were fertilized at $\geq 11 \mathrm{ppt}$. The findings were related to poor cod recruitment in years of low salinity in the Baltic Sea. Nissling and Westin (1997) also showed that Belt Sea and Baltic Sea cod differed in sperm motility and this variation was characteristic of the salinity differences of the area the adults inhabited.

The role that ovarian fluid plays in influencing motility and fertilization success has recently been studied (Litvak and Trippel, 1998). It was revealed that cod sperm motility is enhanced when diluted 

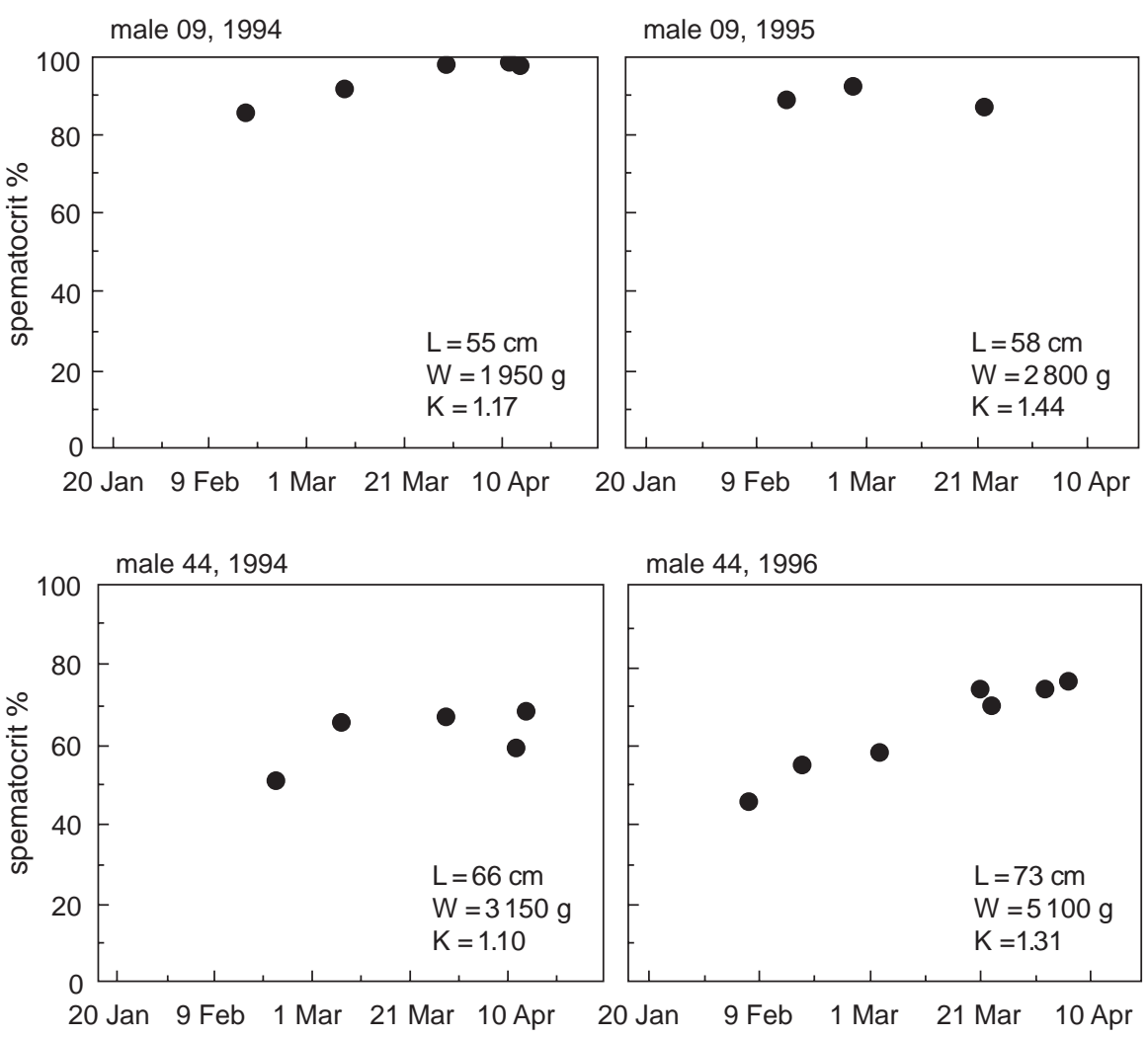

Fig. 8. Seasonal and annual variation of spermatocrit of two Atlantic cod. Each point is the mean of three measurements of spermatocrit from a semen sample. L: total length, W: body weight, and K: Fulton's condition factor. (Reproduced from A. Rakitin, M. M. Ferguson, and E. A. Trippel. 1999. Spermatocrit, spermatozoa density and size in Atlantic cod (Gadus morhua): correlation and variation during the spawning season. Aquaculture, 170: 349-358. Copyright 1999, with permission from Elsevier Science.)

semen was placed in ovarian fluid or directly on the egg's surface still coated by ovarian fluid compared to seawater alone. Eggs, ovarian fluid, sperm, seminal fluid and seawater become mixed when genital pores are closely aligned during spawning. The ovarian fluid contribution to the gamete mixture may improve chances for fertilization, such that sperm can be activated or their velocity enhanced when in contact with maternal substances (Amanze and Iyengar, 1990; Litvak and Trippel, 1998). Note, turbot sperm motility (duration) approximately doubled when males were kept in captivity with other females as compared to being in isolation (Suquet et al., 1992b) and a lengthier period of herring sperm motility occurred in the presence of eggs (Geffen, 1999). These maternal aspects are not considered in standardized practices used to assess sperm motility (Trippel and Neilson, 1992; Billard et al., 1995; Chauvaud et al., 1995). The absence of maternal substances in estimation of sperm motility of Baltic cod by Westin and Nissling (1991) may explain why fertilization was achieved at low salinities (5-7 ppt), despite immotility of sperm at these salinities.

Trippel and Morgan (1994b) showed that cod sperm held in seawater for $1 \mathrm{hr}$ maintained high fertilization success when brought into contact with fresh eggs (i.e., previously unexposed to seawater), indicating prolonged sperm longevity in this species (Fig. 5). This facet of spawning differs from freshwater teleosts in which gamete longevity in water is commonly $<1$ min (Billard and Cosson, 1992; Hoysak and Liley, 2001). Extended sperm longevity may have some adaptive importance in large dense spawning aggregations (Hourston and Rosenthal, 1976; Morgan and Trippel, 1996; Nordeide and Kjellsby, 1999). Considering the lengthy time (several minutes) it takes for an individual female to release a large egg batch 
(Fordham and Trippel, 1999; Rakitin et al., 2001; $3 \mathrm{~min}$ for $500 \mathrm{ml}$ or $\sim 200,000 \mathrm{eggs}$ ), it is possible that viable unfertilized eggs that are able to maintain their fertilization capacity for $1 \mathrm{hr}$ in sea water (Kjørsvik and Lønning, 1983) could be adrift within the cod spawning assemblage and be subsequently fertilized by drifting viable sperm from other distant males (Fig. 9). This alternative form of fertilization differs from that previously referred to involving satellite males in close contact with a spawning female (Hutchings et al., 1999).

A review of sperm quality in relation to paternal age and reproductive experience of freshwater and marine fishes was previously performed (Trippel and Neilson, 1992). Investigators showed that age and size at sexual maturity could influence sperm motility in some species, though for others no trend with reproductive experience existed. A recent study on sockeye salmon (Oncorhynchus nerka) reported sperm from males of various ages differed little in motility and did not differ at all in their ability to fertilize eggs (Hoysak and Liley, 2001). Few studies have examined sperm fertilization capacity in diluted seawater mixtures (e.g., herring, Rosenthal et al., 1988 (Fig.10); Atlantic cod, Trippel and Neilson, 1992). Consequently, the application of sperm motility estimates to the estimation of stock reproductive potential is still in need of further investigation. Clearer understanding of the role of paternal-maternal interactions among germ cells is required (Yanagimachi et al., 1992; Takborsky, 1998). There is a need for studies that challenge sperm in seawater diluted mixtures. Assessment of seasonal changes in sperm motility is also required (Wang and Crim, 1997; Shangguan and Crim, 1999). Ageing of spermatozoa is also an interesting feature of sperm production in many marine fish species. The advantages of possessing motile sperm to more rapidly access the egg's micropyle are significant (Ginsburg, 1968; Levanduski and Cloud, 1988), though specific quantification or ranking of males in association with sperm motility and reproductive potency requires further investigation.

\section{Schematic Representation of Promiscuous Fertilization}

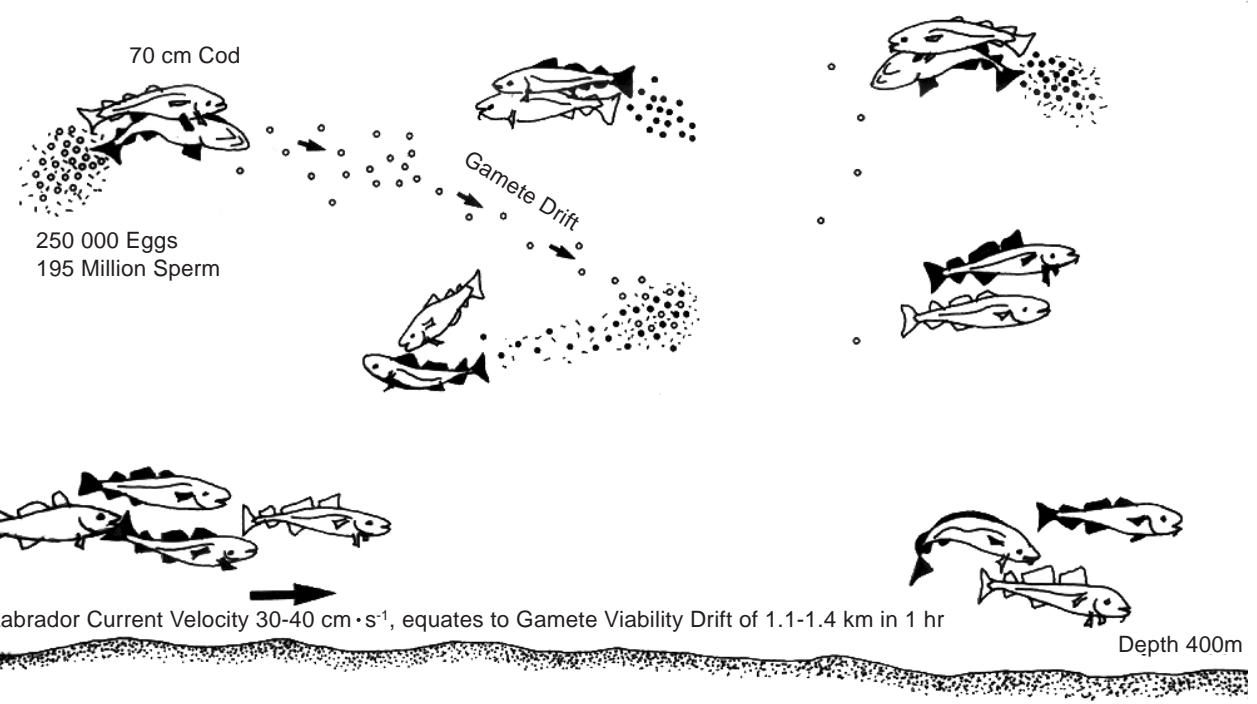

Fig. 9. Schematic illustration of the potential for promiscuous fertilizations to occur as a consequence of extended gamete longevity in both sexes in Atlantic cod. The amount of eggs released in a single batch and the extended longevity in seawater (30-60 min, Kjørsvik and Lønning, 1983) and particularly of sperm (1-3 hr, Trippel and Morgan, 1994b) provide for a broad scope of viable egg:sperm interactions among suspended gametes of various parents. 
Application of Sperm Fertilization Potential Data to Estimation of Stock Viable Sperm Production

This facet of male reproductive potential has clear application to viable stock sperm production estimates. Fertilization potential represents a broad suite of sperm cell characteristics, and conceivably precludes the need to explicitly use sperm motility as a

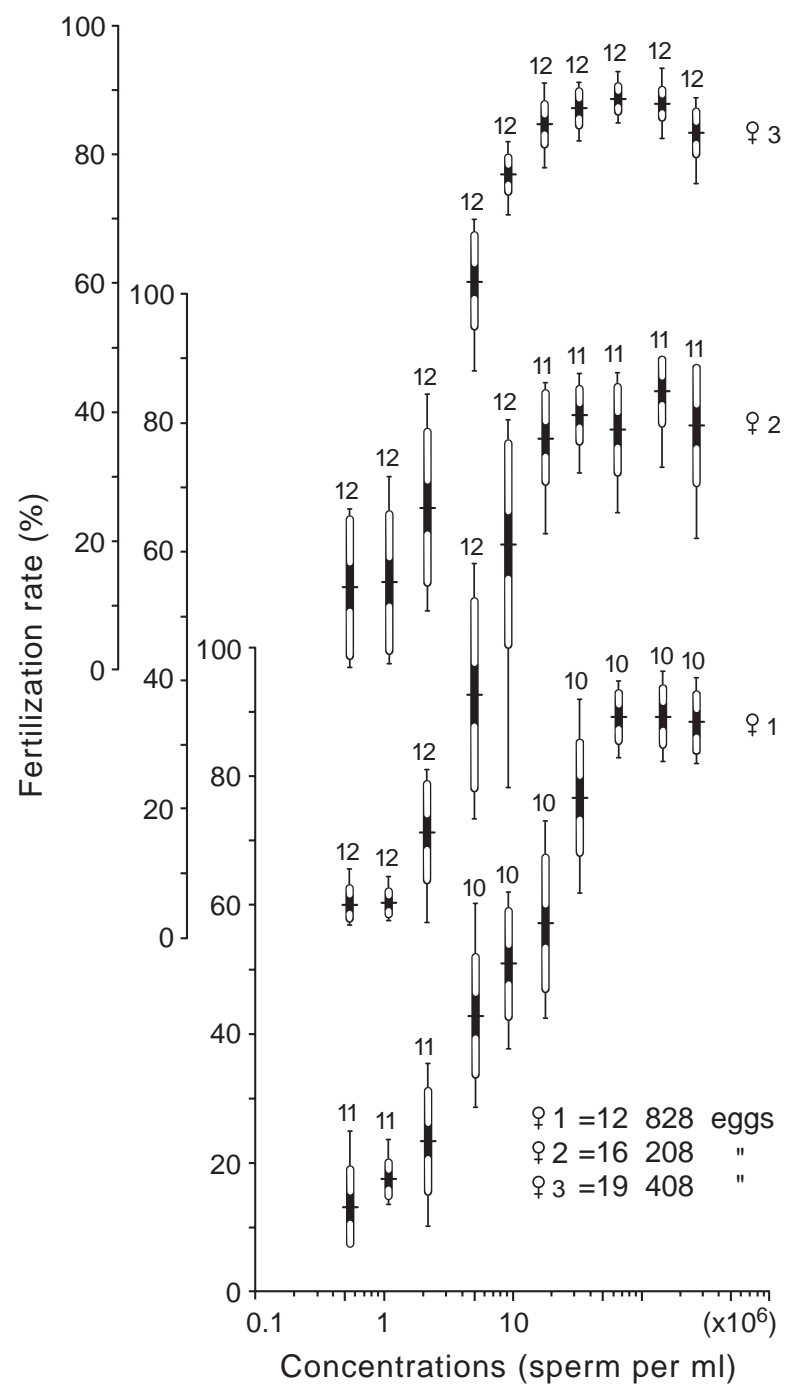

Fig. 10. Relationship between fertilization rate and sperm density of Baltic Sea herring in 10 semen dilution media. Data from three females combined. Vertical lines: range of observations; Open bars: standard deviation; Closed bars: standard error; Numbers over bars indicate the number of replicates. (Reproduced from H. Rosenthal, D. Klump, and J. Willfuhr. 1988. Influence of sperm density and contact time on herring egg fertilization. J. Appl. Ichthyol., 4: 79-86. Copyright 1988, with permission from Blackwell Publishing.) component of viable sperm production. Experimentally derived values from laboratories (either landbased or on a research vessel) are necessary as in most environments it is not readily possible to measure sperm fertilization success of individual males in spawning assemblages (Marconato et al., 1997; Petersen et al., 2001). However, some studies have estimated area-wide egg fertilization rates in population spawning areas (Markle and Waiwood, 1986; Howell et al., 1991). Precautions described by Lambert and Thorsen (2003) in extrapolating findings from captive fish to wild populations also apply to fertilization potential.

\section{Equation of Viable Sperm Production of a Fish Stock}

Several attributes of male reproductive potential have been measured of gadoid, pleuronectoid and clupeid fishes and these studies, including a brief summary of their findings, are presented in Table 1. An initiative towards representing a population's effective sperm production using these data is timely given the state of fish stocks and the growing knowledge of male fish reproduction. In this regard, a generalized equation to estimate a population's annual viable sperm production and male reproductive potential is given for determinant spawning species:

Viable Sperm Produced by Population:

$$
\sum_{i=1}^{I} n_{i} p_{i} t_{i} v_{i} s_{i} f_{i}
$$

where,

$i$ is age (in years),

$I$ is oldest age class

$n_{i}$ is numbers at age $i$,

$p_{i}$ is proportion of sexually mature males that participate in spawning at age $i$,

$t_{i}$ is mean testes weight of fish at age $i$ ( $k g$ testes),

$v_{i}$ is mean volume of semen produced per $\mathrm{kg}$ of testes

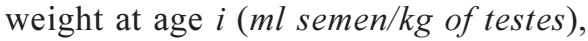

$s_{i}$ is mean number of spermatozoa per $\mathrm{mL}$ of semen from fish at age $i$ (spermatozoa/ml semen),

$f_{i}$ is sperm fertilization potential as a function of e.g., condition factor $K$ at age $i, f\left(K_{i}\right)$.

This equation incorporates a number of aspects of male reproduction and is intended to be applied to a variety of determinant spawning species. It represents the abundance and biomass of sexually mature males of each age group in a given year in a 


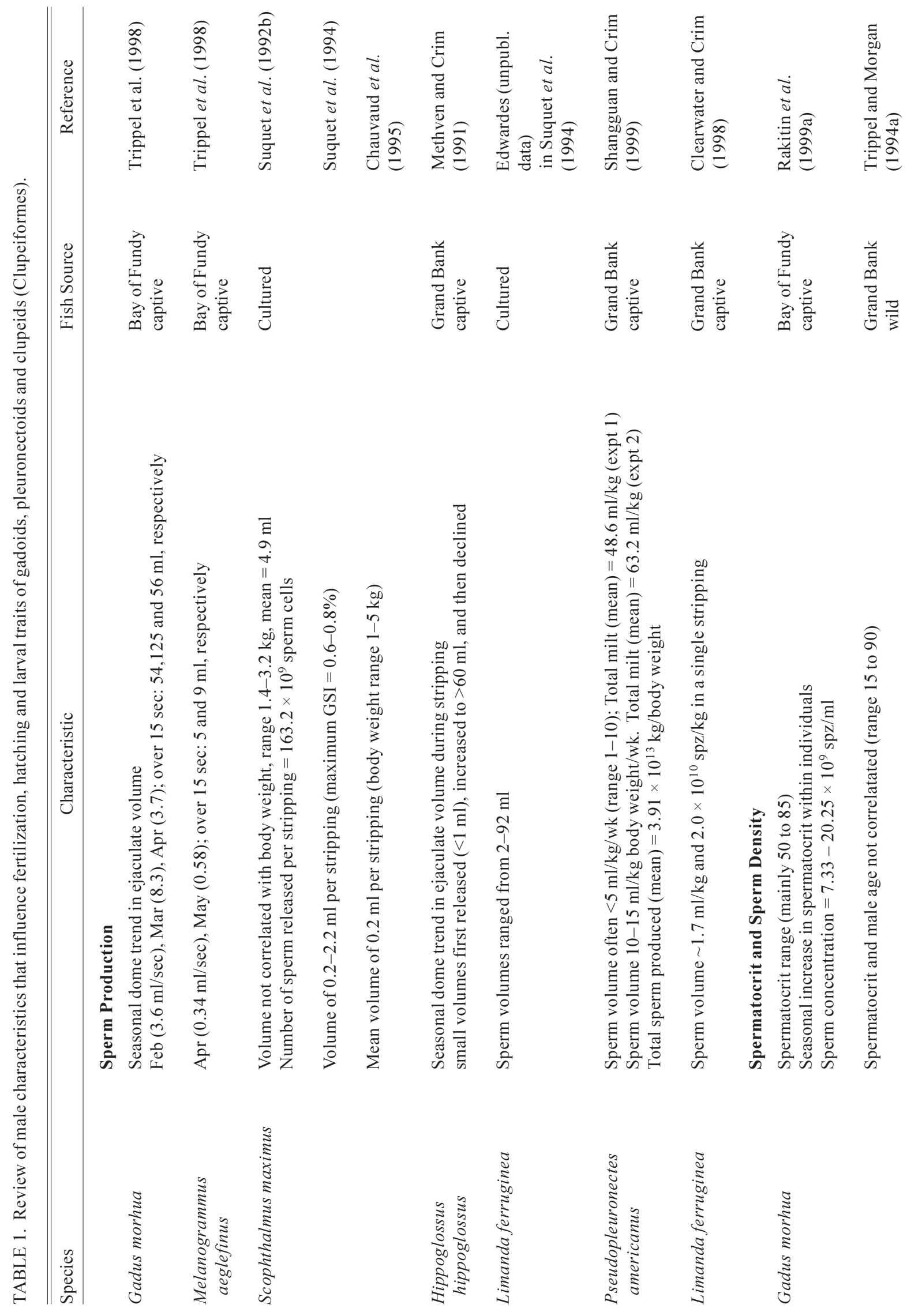




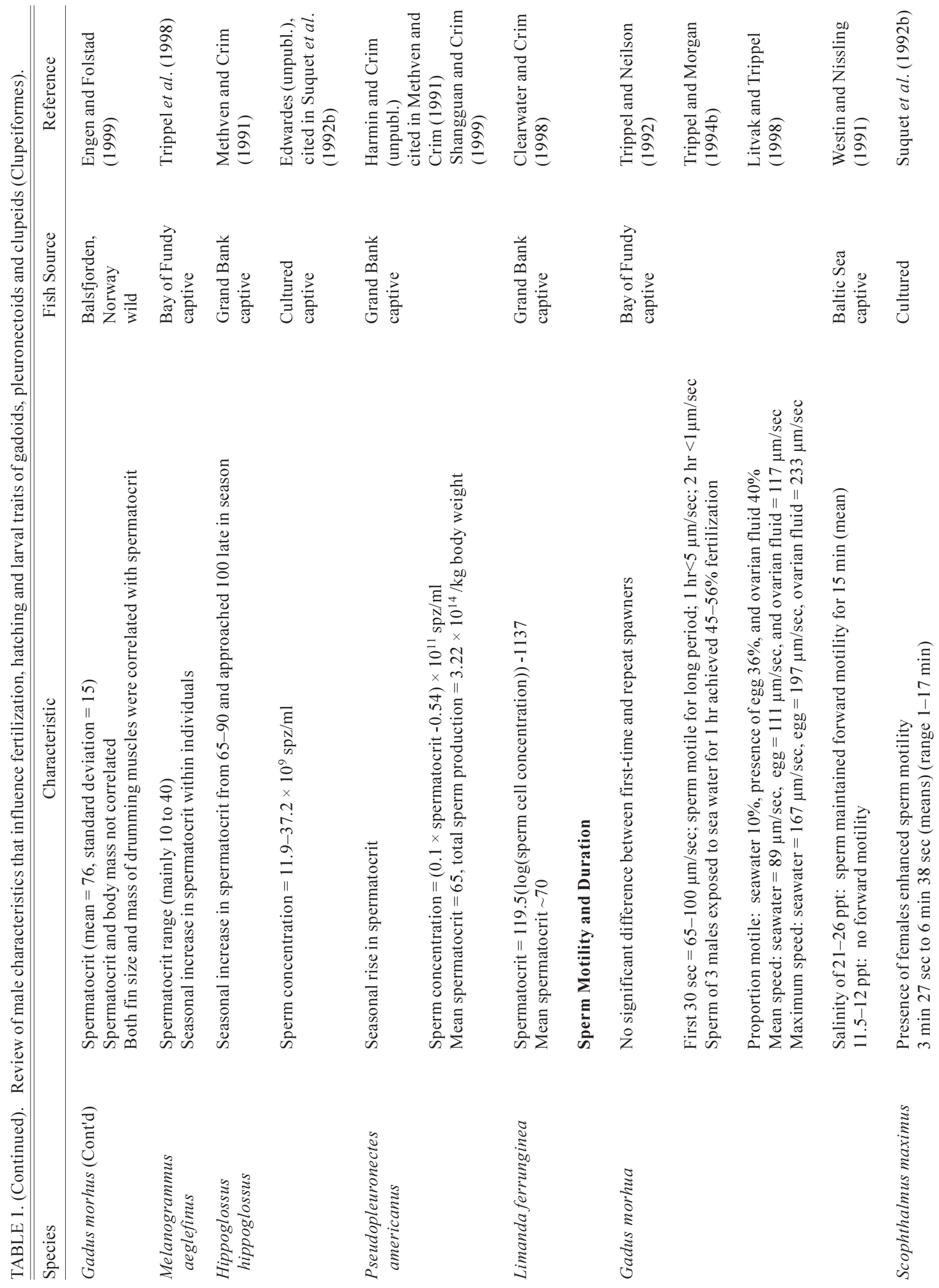




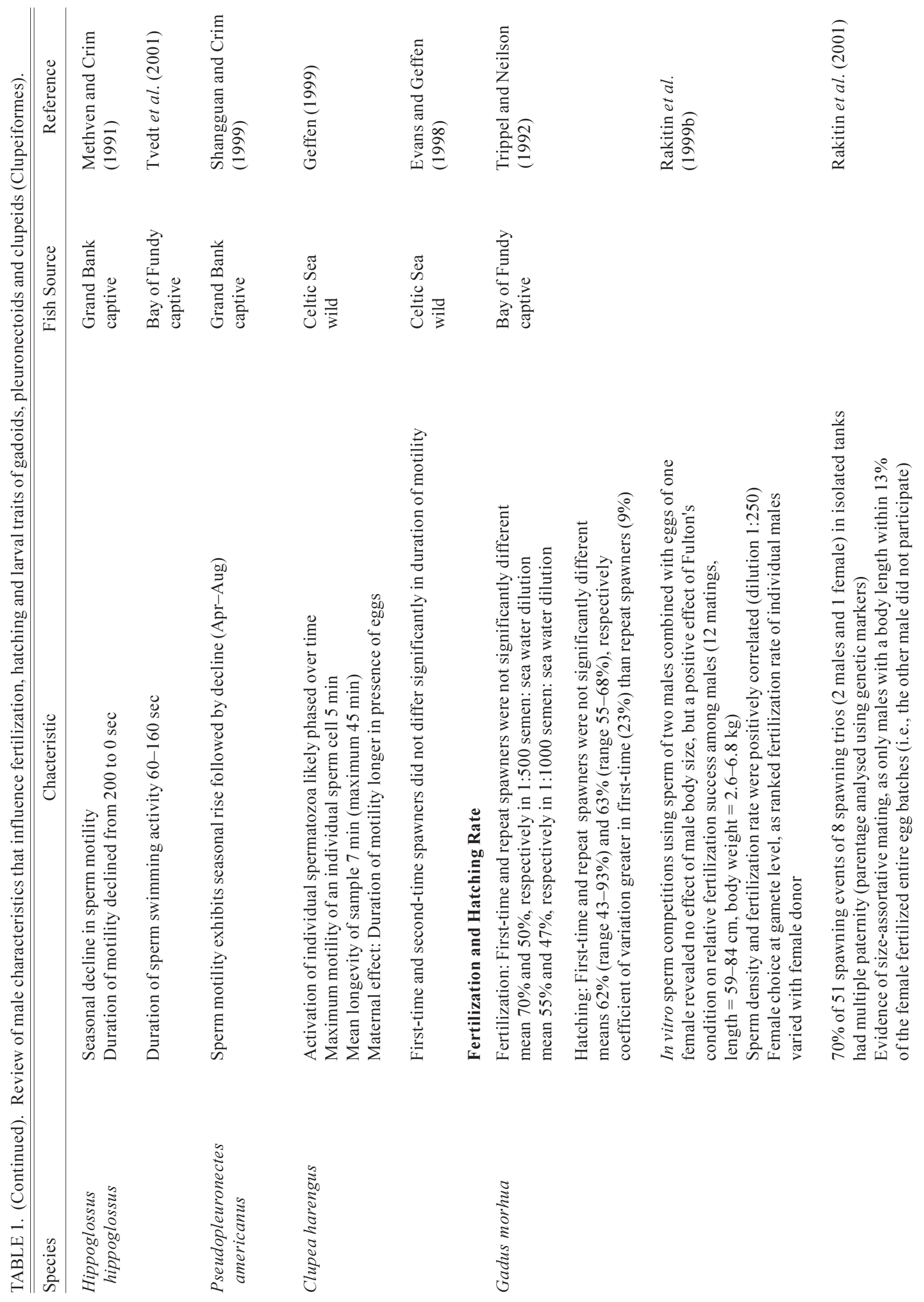


TRIPPEL: Male Reproductive Success

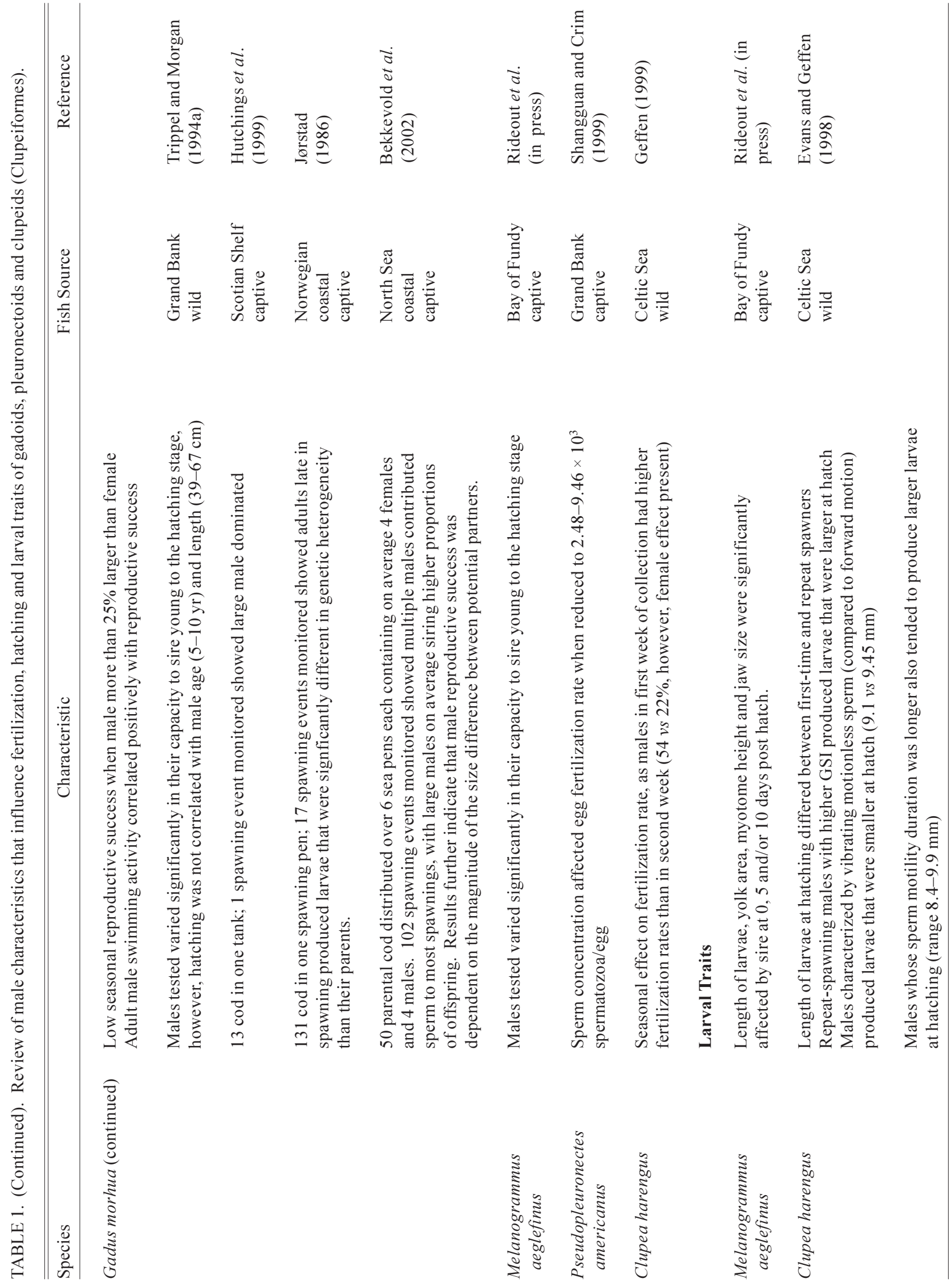


fish stock, and adjusts for, where necessary, the failure of certain segments of a population to release sperm that subsequently undergo testicular atresia. Variables in the equation exist that represent testes weight and the associated volume of semen by male age. The number of sperm released by each age class is then estimated by simple adjustments of number sperm per unit volume. Lastly, an important aspect is their fertilization potential, which is estimated from experimental procedures and related to a body metric such as male condition factor. For example, fish in poor condition may produce fewer sperm due to lower allocation to reproduction, and these may be of poor viability (i.e., via reduced swimming speed).

\section{Example: Viable Sperm Production of Newfoundland and Labrador Cod}

\section{Available data}

Population data on cod of Newfoundland and Labrabor (NAFO Division 2J3KL) and experimental findings on captive cod of the Bay of Fundy (NAFO Division 4X) were integrated to generate a time series of male reproductive potential for Div. 2J3KL cod (i.e., the number of viable sperm produced per year) using the above equation. Population statistics of Div. 2J3KL cod were taken from Department of Fisheries and Oceans, Canada, stock assessment documents (Lilly, MS 1996; Shelton et al., MS 1996; Lilly et al., MS 2000). When data were missing (e.g., condition factor, weight-at-age or maturity) values were taken from the same age fish from the nearest previous year with data. If no data existed from the previous year, data from the nearest year before that were used. Cohort numbers existed to age 13 (Shelton et al., MS 1996) while some data extended only to age 12 . In these cases, we assumed age 12 values for age 13 fish.

Data on the number at age of cod (1978-95) were taken from the virtual population analysis of the Div. 2J3KL cod stock assessment (Shelton et al., MS 1996). Mean weights-at-age were taken from cod caught during the autumn bottom-trawl surveys (Shelton et al., MS 1996). Mean weights at age were calculated with a weighted average (by stratified total numbers) of mean weight-at-age of each NAFO Division.

A 50:50 sex ratio in the population was assumed. Data on proportion mature at age for males (1982-84 and 1986-95) were taken from the research survey data (Trippel et al., 1997a). These values were used to estimate mature biomass of males. Not all sexually mature males participate in spawning, as evidence indicates small first-time spawning males (age $3 \mathrm{yr}$ ) do not release sperm (Trippel and Morgan, 1994a) and likely undergo testicular atresia (Rideout et al., 2000). These males were included in estimates of male spawning stock biomass but excluded from data used to estimate sperm production.

Mean testes weight per kg of fish at each age was determined from an age-gonadosomatic index (GSI) relationship representing a positive association of gonadal investment with an increase in age (Trippel and Morgan, 1994a). Three percent of testes weight was assumed to be connective tissue, primary spermagonia, and residual unspawned sperm (Trippel and Morgan, 1994a), the residual sperm is presumably resorbed as GSI declines to $1 \%$ in early autumn (Rideout and Burton, 2000). Weight of semen was converted to volume by multiplying by a factor of 1.04 (given its higher density than water; E.A. Trippel, unpubl. data). This conversion was based on a spermatocrit of 0.60 (the approximate mean value of cod semen for the Grand Bank (Trippel and Morgan, 1994a) and is similar to Bay of Fundy cod (Trippel et al., 1998; Rakitin et al., 1999a). No age or body size relationship existed with spermatocrit (Trippel and Morgan, 1994a), although it is known to increase within individuals as the spawning season progresses (Rakitin et al., 1999a). The number of sperm per ml of semen was estimated using the equation of Rakitin et al. (1999a) developed for Bay of Fundy cod. There exist $1.16 \times 10^{10}$ sperm in one $\mathrm{ml}$ of semen having a spermatocrit of 0.60 . The longer spawning season of older males of the Grand Bank (Trippel and Morgan, 1994a) was not separately factored in, but the relationship is probably highly correlated with the GSI-age relationship, i.e., a long spawning period provides for improved chances of recruitment (Hutchings and Myers, 1993; Trippel et al., 1997b). Atlantic cod is a determinate spawner (Rideout and Burton, 2000) and thus mature testes weight could be used as a good proxy of annual semen production.

Sperm fertilization potential was not dependent on age and first-time spawning (Trippel and Neilson, 1992; Trippel and Morgan, 1994a) which is in contrast to egg quality (Trippel, 1998). However, fertilization potential has been shown to be positively correlated with male condition factor (Rakitin et al., 1999b). Mean annual condition factor at age $\left(K_{i}\right)$ was calculated through a weighted mean (weighted by NAFO Division specific abundance) of Fulton's 
condition factor at age $\left(K_{i h}\right)$ of cod (Lilly, MS 1996) from each NAFO Division as follows.

$$
K_{i}=\sum_{h=1}^{H}\left(K_{i h} \frac{n_{i h}}{n_{i}}\right)
$$

where,

$i$ is age (in years)

$h$ is Division (i.e., $2 \mathrm{~J}, 3 \mathrm{~K}$, and $3 \mathrm{~L}$ )

$H$ is total number of Divisions i.e., 3

$K_{i}$ is mean annual condition factor at age $i$

$K_{i h}$ is annual condition factor at age $i$ in NAFO Division $h$

$n_{i h}$ is abundance at age $i$ in NAFO Division $h$

$n_{i}$ is total abundance at age $i$ in the stock

Fertilization potential of cod sperm $(f)$ is generally between 0.30 and 0.70 (Trippel and Neilson, 1992). Estimates of fertilization potential were created from the mean annual condition factor at age $\left(K_{i}\right)$ by the linear model, $f=1.554\left(K_{i}\right)-1.028$. This relationship allowed fertilization potential in the Div. 2J3KL cod stock to vary between 0.30 and 0.70 .

\section{Results}

The number of sperm cells released by mature male cod of Newfoundland and Labrador (mean sperm/male) was highly variable through the study period (Fig. 11). Both total sperm per mature male and viable sperm per mature male reached a maximum in 1981 of $3.72 \times 10^{12}$ and $1.84 \times 10^{12}$, respectively and a minimum in 1993 of $1.81 \times 10^{12}$ and $0.79 \times$ $10^{12}$, respectively. The high and low periods of total sperm per mature male refer to $322 \mathrm{ml}$ and $156 \mathrm{ml}$ of semen/mature male, respectively and a population total of 63.9 million and 1.7 million liters of semen, respectively. During this period, mean age and mean condition factor of the stock declined (Lilly, MS 1996; Shelton et al., MS 1996). A closer association was observed between abundance of age 3 recruits and viable sperm production than between age 3 recruits and spawning stock biomass (Fig. 12). Specifically, mature stock biomass and age 3 recruits were poorly correlated and not significant having a $r^{2}=0.082$, $P=0.30$ using linear regression analysis without passing through the origin. The regression between viable sperm and age 3 recruits created a marginal improvement in amount of variation explained $\left(r^{2}=\right.$ $0.139, P=0.17)$. Distinct peaks in the number of viable sperm in 1981 and 1986 corresponded to distinct peaks in the number of age 3 recruits in those same years (Fig. 12). From the viable sperm - age 3 relationship, the number of sperm to generate one

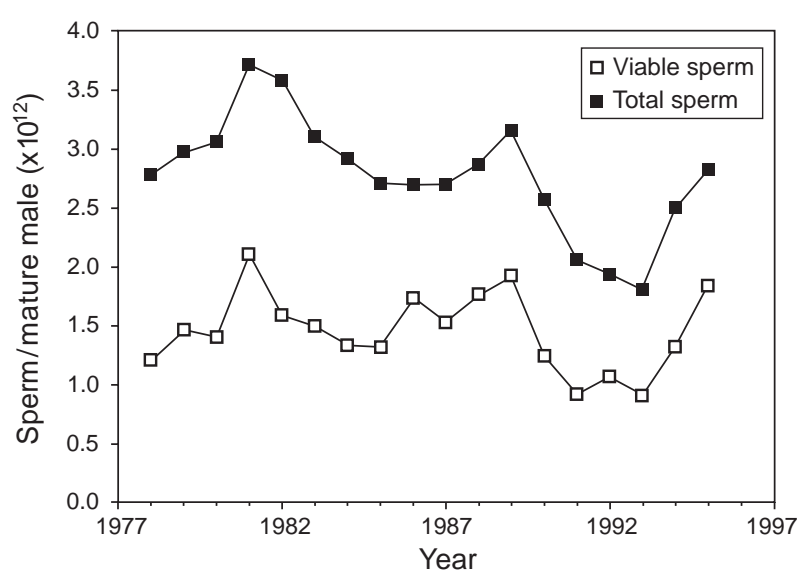

Fig. 11. Number of sperm produced per mature male by Atlantic cod in NAFO Divisions 2J3KL.

recruit (age 3 ) was estimated to be $1.60 \times 10^{12}$, i.e., 1600 billion sperm on average (equation: age 3 recruits $=1.07 \times 10^{-12}($ viable sperm $\left.)+1.88 \times 10^{7}\right)$.

\section{Discussion}

This example is not intended to indicate that sperm production is superior to egg production as a predictor of recruitment. Spawning stock biomass has been commonly used as a rough approximation of egg production, and this approach in itself has come under much criticism (e.g., Marshall et al., 2003; O'Brien et al., 2003; Mukhina et al., 2003).

This is a preliminary attempt to estimate viable sperm production across a time series of a fish stock. In our example, there exist obvious gaps in the available data, and several assumptions were made accordingly. Skewed sex ratios of sets towards each sex exist in surveys and in part are related to the formation of spawning shoals (Morgan and Trippel, 1996). Evidence indicates females dominate the older age group (>10 yr) of Georges Bank (Hunt, 1996) and Northeast Arctic cod (Jakobsen and Ajiad, 1999), partly due to their longevity. Analysis of Div. 2J3KL cod indicates a smoothed sex ratio range of 0.43 to 0.53 (maximum 9\% difference) (Morgan, MS 2000). Further effort to incorporate annual age-specific sex ratio data is recommended. Effort could be placed on recording data of pre-spawning mature testes weight to further refine the relative allocation of energy to reproduction in relation to body size and age. The process of integrating experimental and field data has been applied for female components (e.g., Murawski et al., 2001; Marteinsdottir and Begg, 2002) and is a resourceful approach to understanding recruitment. 


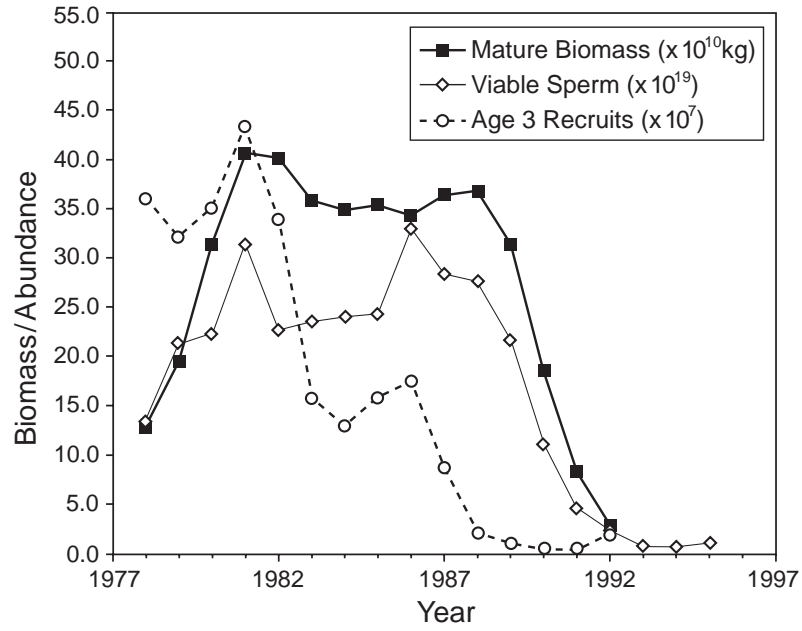

Fig. 12. Temporal trend in mature stock biomass, viable sperm production, and age 3 recruits produced for Atlantic cod in NAFO Divisions 2J3KL.

The extent that an enormously abundant quantity of viable sperm, compared to expelled eggs, in some way further influences recruitment is of interest and relevance. This analysis suggests there are some gains to be made in estimating reproductive potential in this regard. Further analyses of interest may reside in populations where sex-selective harvesting over many generations has taken place resulting in skewed sex ratios of a stock. The interaction of gamete quality of both sexes also lends itself to further research that generates a more complete picture of the spawning potential of a fish stock and its possible influence on recruitment (e.g., annual estimation of fertilized egg production). Moreover, parental effects on egg mortality may be dependent on which female was mated with which male, introducing additional variation (Wedekind et al., 2001; Saillant et al., 2001).

The use of underlying condition, age structure, fertility, and GSI indicate a possible application of estimation of male reproductive success in understanding and predicting recruitment. Our results highlight the inability of spawning stock biomass for this stock to be considered a reliable representation of stock reproductive potential. In the Div. $2 \mathrm{~J} 3 \mathrm{KL}$ cod stock, mature stock biomass remained relatively stable from 1981-88 and failed to capture the precipitous decline in recruitment which occurred after 1981 (Fig. 12). Viable sperm was sensitive to this decline for one year (1982) after which recruitment continued to decline while viable sperm and mature stock biomass remained relatively stable. This is similar to a secondary decline in recruitment in 1986 after which recruitment was not well represented by measures of viable sperm and mature stock biomass. This tends to highlight the fact that the measure of recruitment used (age 3 VPA estimate) is far removed ecologically from measures of stock reproductive potential. It is possible that measures of reproductive potential of a population can adequately describe recruitment events closer in time to reproduction (e.g., larval recruitment). However, much opportunity exists for other processes to act on cohorts before reaching age 3 , such as natural and undirected fishing mortality. Prediction of recruitment variation of some fish stocks has been improved by integration of characteristics of population demography and energetics (Murawski et al., 2001; Marshall et al., 2003). For Div. 2J3KL cod, partitioning of male reproductive potential and application of an equation resulted in greater explanatory power over spawning stock biomass, but still inadequately described recruitment patterns.

It is unclear at this point whether the possible usefulness of the male reproductive equation would be a result of the measure of viable sperm per se or whether it would be the result of the explicit incorporation of variables such as age structure, maturity, and condition factor. Either way, these variables have been incorporated in an informative and biologically meaningful way. Further, this measure of male reproductive potential provides a promising framework that can be used to explore the relationship between reproductive output of a population and recruitment.

Assessment of male reproductive potential for use in stock-recruitment relationships is in its early stages of development. As reviewed, characterization of sperm quality and fertilization potential demand detailed experimentation, and are not without associated shortcomings. Some aspects of male fitness are presently easily measured and can be used to estimate reproductive potential. For example, the mature testes of ripe unspawned males could be weighed and spermatocrit determined of stripped semen in the case of determinate spawners. Thus, for an individual, testes weight could be used to represent sperm output (volume of milt) and when multiplied by spermatocrit could be used as a proxy for an individual's total seasonal sperm output (positive correlations exist between testes weight and volume as well as between spermatocrit and sperm density). Experimental research on male fertilization potential and the impact of sire body characteristics on hatching 
and larval traits could then be used to integrate sperm quality with quantity and evaluate male impact on reproductive success.

Aspects of spawning that are also important and require further study include factors governing male participation in the spawning act. Female choice may additionally result in the selection of the "best" males in a population. Hence, integrating lesser males in the estimation of stock reproductive potential may be of limited value, particularly if a single male is capable of fertilizing all of the ova of several females. Monopolization of egg fertilization by a single male may be the norm, but it is also common to observe additional males join in a spawning act initiated by a "dominant male" (Hutchings et al., 1999; J.A. Hutchings, pers. comm.). Estimating male fertility within a population may therefore only serve as an estimate of the potential ability of sires to affect progeny production and fitness, as knowledge of the mating dynamics in natural aggregations is incomplete. Nonetheless, documentation of widespread variation in sperm quality and quantity in a population or between years would begin to alert investigators that variability in female spawning success could be impacted by the male gender. Further segregation of sperm production by specific components of the population may also be an area to pursue. Aspects such as the lack of large males to match the long spawning season of large females could be a limiting factor of recruitment (though total sperm production of the population may not). A sensitivity analysis could be conducted to examine the relative degree of influence of each factor in the model on total viable sperm production. For example, one could test the impact of different male characteristics on stock reproductive potential. Synergistic interactions linked to poor gamete quality of both sexes (e.g., due to low condition) could cause further reduction in fertilization success and the quality of offspring and inevitably recruitment success. The study of male parental traits and sperm quality/quantity and their role in recruitment variability is thus a challenging area of fishery science and if investigated further will assist in broadening our knowledge of reproductive processes at the population level.

\section{Acknowledgements}

I thank J. A. Hutchings and M. Suquet for their constructive comments. Rabea Diekmann and Travis Shepherd assisted with figure preparation and model development. The manuscript was prepared while the author was on professional development leave at the
Institute of Marine Sciences, University of Kiel, Germany. Jonna Tomkiewicz took on the editorial role of this contribution as part of the NAFO Working Group on Reproductive Potential and her fine effort in this regard is very much appreciated.

\section{References}

AMANZE, D., and A. IYENGAR. 1990. The micropyle: a sperm guidance system in teleost fertilization. Development (Camb.), 109: 495-500.

BABIAK, I., J. GLOGOWSKI, M. LUCZYNSKI, K. GORYCZKO, S. DOBOSZ, and H. KUZMINSKI. 1998. The effect of individual male potency on fertilization ability of fresh and cryopreserved milt of rainbow trout, Oncorhynchus mykiss (Walbaum). Aquacult. Res., 29: 337-340.

BAGENAL, T. B. 1973. Fish fecundity and its relations with stock and recruitment. ICES Rapp. Proc.-Verb., 164: $186-198$.

BARTON, B. A, and G. K. IWAMA. 1991. Physiological changes in fish from stress in aquaculture with emphasis on the response and effects of corticosteroids. Ann. Rev. Fish Disea., 1: 3-26.

BENGTSON, D. A., R. C. BARKMAN, and W. J. BERRY. 1987. Relationships between maternal size, egg diameter, time of spawning season, temperature, and length at hatch of Atlantic silverside, Menidia menidia. J. Fish Biol., 31: 697-704.

BENTZEN, P., C. T. TAGGART, D. E. RUZZANTE, and D. COOK. 1996. Microsatellite polymorphism and the population structure of Atlantic cod (Gadus morhua) in the northwest Atlantic. Can. J. Fish. Aquat. Sci., 53: 2706-2721.

BEKKEVOLD, D., M. M. HANSEN, and V. LOESCHCKE. 2002. Male reproductive competition in spawning aggregations of cod (Gadus morhua L.). Mol. Ecol. 11: $91-102$.

BERNER, M. 1985. The periodic changes in gonad weight and spawning cycle of the "Baltic" and "Belt cod" (G. morhua callarias/G. morhua morhua) in different regions of the Baltic. Can. Transl. Fish. Aquat. Sci. No. 5604. 23 p.

BILLARD, R. 1981. Short-term preservation of sperm under oxygen atmosphere in rainbow trout (Salmo gairdneri). Aquaculture, 23: 287-293.

1986. Spermatogenesis and spermatology of some teleost fish species. Reprod. Nutr. Develop., 26: 877-920.

BILLARD, R., C. BRY, and C. GILLET. 1981. Stress, environment and reproduction in teleost fish. In: Stress and fish. A. D. Pickering (ed.). Academic Press, London, p. 185-208.

BILLARD, R., and J. COSSON. 1992. Some problems related to the assessment of sperm motility in freshwater fish. J. Exp. Zool., 261: 122-131.

BILLARD, R., J. COSSON, L. W. CRIM, and M. SUQUET. 1995. Sperm physiology and quality. In: Broodstock management and egg and larval quality, N.R. Bromage 
and R.J. Roberts (eds.). University Press, Cambridge, p. $25-52$.

BILLARD, R., J. COSSON, and L. W. CRIM. 1993. Motility of fresh and aged halibut sperm. Aquat. Living Resour., 6: $67-75$.

BILLARD, R., O. LINHART, F. FIERVILLE, and J. COSSON. 1997. Motility of European catfish Silurus glanis spermatozoa in testes and in milt. Pol. Arch. Hydrobiol., 44: 115-122.

BLAXTER, J. H. S., and G. HEMPEL. 1963. The influence of egg size on herring larvae (Clupea harengus L.). J. Cons. Perm. Int. Explor. Mer, 28: 211-240.

BOUCK, G. G., and J. JACOBSON. 1976. Estimation of salmonid sperm concentration by microhematocrit technique. Trans. Am. Fish. Soc., 105: 534-535.

BRAWN, V. M. 1961a. Reproductive behaviour of the cod (Gadus callarias L.) Behaviour, 18: 177-198.

$1961 b$. Sound production by the cod (Gadus callarias L.). Behaviour, 18: 239-245.

BREMNER, A. M., E. A. TRIPPEL, and J. A. TERHUNE. 2002. Sound production of adult haddock (Melanogrammus aeglefinus) in isolation, pairs and trios. Environ. Biol. Fish., 65: 359-362.

BRULE, T., C. DENIEL, T. COLAS-MARRUFO, and M. SANCHEZ-CRESPO. 1999. Red grouper reproduction in the southern Gulf of Mexico. Trans. Am. Fish. Soc., 128: 385-402.

BURTON, M. P. M., and S. R. FLYNN. 1998. Differential postspawning mortality among male and female capelin (Mallotus villosus Mueller) in captivity. Can. J. Zool., 76: 588-592.

BURTON, M. P., and D. R. IDLER. 1984. The reproductive cycle in winter flounder, Pseudopleuronectes americanus (Walbaum). Can. J. Zool., 62: 2563-2567.

BURTON, M. P. M., R. M. A. PENNEY, and S. BIDDISCOMBE. 1997. Time course of gametogenesis in Northwest Atlantic cod (Gadus morhua). Can. J. Fish. Aquat. Sci., 54 (Suppl. 1): 122-131.

CARDINALE, M., and F. ARRHENIUS. 2000. The relationship between stock and recruitment: are the assumptions valid? Mar. Ecol. Prog. Ser., 196: 305-309.

CARDINALE, M., and J. MODIN. 1999. Changes in size-atmaturity of Baltic cod (Gadus morhua) during a period of large variations in stock size and environmental conditions. Fish. Res., 41: 285-295.

CHAMBERS, R. C. 1997. Environmental influences on egg and propagule sizes in marine fishes. In: Early life history and recruitment in fish populations, R. C. Chambers and E. A. Trippel (eds.). Chapman and Hall, London, p. $63-102$.

CHAMBERS, R. C., and W. L. LEGGETT. 1992. Possible causes and consequences of variation in age and size at metamorphosis in flatfishes (Pleuronectiformes): an analysis at the individual, population, and species levels. Netherlands Journal of Sea Research, 29: 7-24.

1996. Maternal influences on variation in egg sizes in temperate marine fishes. Amer. Zool., 36: 180-196.

CHAMBERS, R. C., W. C. LEGGETT, and J. A. BROWN. 1988. Variation in and among early life history traits of laboratory-reared winter flounder Pseudopleuronectes americanus. Mar. Ecol. Prog. Ser., 47: 1-15.

CHAUVAUD, L., J. COSSON, M. SUQUET, and R. BILLARD. 1995. Sperm motility in turbot, Scophthalmus maximus: initiation of movement and changes with time of swimming characteristics. Environ. Biol. Fish., 43: 341-349.

CHEREGUINI, O., de la BANDA, I. G., I. RASINES, and A. FERNANDEZ. 1999. Artificial fertilization in turbot, Scophthalmus maximus (L.): different methods and determination of the optimal sperm-egg ratio. Aquacult. Res., 30: 319-324.

CIERESZKO, A., and K. DABROWSKI. 1993. Estimation of sperm concentration of rainbow trout, whitefish and yellow perch using a spectrophotometric technique. Aquaculture, 109: 367-373.

CIERESZKO, A., J. GLOGOWSKI, J., and K. DABROWSKI. 2000. Fertilization in landlocked sea lamprey: storage of gametes, optimal sperm: egg ratio, and methods of assessing fertilization success. J. Fish Biol., 56: 495505.

CLEARWATER, S. J., and L. W. CRIM. 1998. Gonadotropin releasing hormone-analogue treatment increases sperm motility, seminal plasma $\mathrm{pH}$ and sperm production in yellowtail flounder Pleuronectes ferrugineus. Fish Physiol. Biochem., 19: 349-357.

CLEMMESEN, C., V. BÜHLER, G. CARVALHO, R. CASE, G. EVANS, L. HAUSER, W.F. HUTCHINSON, O.S KJESBU, H. MEMPEL, E. MOKSNESS, H. OTTERAA, H., PAULSEN, A. THORSEN, and T. SVAASAND. 2003. Variability in condition and growth of Atlantic cod larvae and juveniles reared in mesocosms: environmental and maternal effects. J. Fish Biol., 62: 706-723.

COSSON, J., R. BILLARD, C. CILBERT, C. DREANNO, O. LINHART, and M. SUQUET. 1997. Movements of fish sperm flagella studied by high speed videomicroscopy coupled to computer assisted image analysis. Pol. Arch. Hydrobiol., 44: 103-113.

DEVAUCHELLE, N., J. C. ALEXANDRE, N. LECORRE, and Y. LETTY. 1988. Spawning of turbot (Scophthalmus maximus) in captivity. Aquaculture, 69: 159-184.

DREANNO; C., M. SUQUET, E. DESBRUYERES, J. COSSON, H. LE DELLIOU, and R. BILLARD. 1998. Effect of urine on semen quality in turbot (Psetta maxima). Aquaculture, 169: 247-262.

ENGEN, F., and I. FOLSTAD. 1999. Cod courtship song: a song at the expense of dance? Can. J. Zool., 77: 542-550.

EVANS, J. P., and A. J. GEFFEN. 1998. Male characteristics, sperm traits, and reproductive success in winter-spawning Celtic Sea Atlantic herring, Clupea harengus. Mar. Biol., 132: $179-186$.

EVANS, J. P., and A. E. MAGURRAN. 1999. Male mating behaviour and sperm production characteristics under varying sperm competition risk in guppies. Anim. Behav., 58: 1001-1006.

FORDHAM, S. E., and E. A. TRIPPEL. 1999. Feeding behaviour of cod (Gadus morhua) in relation to spawning. J. Appl. Ichthyol., 15: 1-9. 
FRIDEREISSON, E., 1978. Embryonic development of five species of gadoid fishes in Icelandic waters. Rit Fiskideildar, 5: 1-68.

GARCIA, L. M. B. 1991. Spermiation response of mature rabbitfish, Syganus guttatus Bloch, to leutenizing hormone-releasing hormone analogue (LHRHa) injection. Aquaculture, 97: 291-299.

GEFFEN, A. J. 1999. Variations in sperm motility of the Atlantic herring Clupea harengus. Mar. Biol., 134: 637-643.

GILE, S. R., and M. M. FERGUSON. 1995. Factors affecting male potency in pooled gamete crosses of rainbow trout (Oncorhynchus mykiss). Environ. Biol. Fish. 42: 267-275.

GILKEY, J. C. 1981. Mechanisms of fertilization in fishes. Am. Zool., 21: 359-375.

GINSBURG, A. S. 1968. Fertilization in fishes and the problem of polyspermy. Dokl. Akad. Nauk SSSR. (Translated from Russian: Israel Program for Scientific Translations Ltd. Jerusalem 1972) $366 \mathrm{p}$.

GLOGOWSKI, J., I. BABIAK, D. KUCHARCZYK, M. LUCZYNSKI. 1997. The effect of individual male variability on cryopreservation of bream (Abramis brama (L.)) sperm. Pol. Arch. Hydrobiol.. 44: 281-285.

GLOGOWSKI, J., I. BABIAK, D. KUCHARCZYK, M. LUCZYNSKI, M., and B. PIROS. 1999. Some properties of bream Abramis brama L. sperm and its cryopreservation. Aquacult. Res., 30: 765-772.

GLOGOWSKI, J., M. KWASNIK, B. PIROS, K. DABROWSKI, K. GORYCZKO, S. DOBOSZ, H. KUZMINSKI, and A. CIERESZKO. 2000. Characterization of rainbow trout milt collected with a catheter: semen parameters and cryopreservation success. Aquacult. Res., 31: 289-296.

HAWKINS, A. D., and M. C. P. AMORIM. 2000. Spawning sounds of the male haddock, Melanogrammus aeglefinus. Environ. Biol. Fish., 59: 29-41.

HAWKINS, A. D., and K. J. RASMUSSEN. 1978. The calls of gadoid fish. J. Mar. Biol. Assoc. U.K., 58: 891-911.

HERBINGER, C. M., R. W. DOYLE, C. T. TAGGART, S. E. LOCHMANN, A. L. BROOKER, J. M. WRIGHT, and D. COOK. 1997. Family relationships and effective population size in a natural cohort of Atlantic cod (Gadus morhua) larvae. Can. J. Fish. Aquat. Sci., 54 (Suppl. 1): 11-18.

HISLOP, J. R. G., A. P. ROSS, and J. A. GAULD. 1978. Observations on the effects of feeding level on growth and reproduction in haddock, Melanogrammus aeglefinus, in captivity. J. Fish Biol., 13: 85-98.

HOURSTON, A. S., and H. ROSENTHAL. 1976. Sperm density during active spawning of Pacific herring (Clupea harengus pallasi). J. Fish. Res. Board Can., 33: 1788-1790.

HOWELL, B. R., A. R. CHILD, and R. G. HOUGHTON. 1991. Fertilization rate in a natural population of the common sole. ICES J. Mar. Sci., 48: 53-59.

HOYSAK, D. J., and N. R. LILEY. 2001. Fertilization dynamics in sockeye salmon and a comparison of sperm from alternate male phenotypes. J. Fish Biol., 58: 1286-1300.
HUNT, J. J. 1996. Rates of sexual maturation of Atlantic cod in NAFO Division 5Ze and commercial fishery implications. J. Northw. Atl. Fish. Sci., 18: 61-75.

HUTCHINGS, J. A., T. D. BISHOP, and C. R. MCGREGORSHAW. 1999. Spawning behaviour of Atlantic cod, Gadus morhua: evidence of mate competition, mate choice, and a negative effect of fishing. Can. J. Fish. Aquat. Sci., 56: 97-104.

HUTCHINGS, J. A., and R. A. MYERS. 1993. Effect of age on the seasonality of maturation and spawning of Atlantic cod, Gadus morhua, in the Northwest Atlantic. Can. J. Fish. Aquat. Sci., 50: 2468-2474.

ILES, T. D. 1964. The duration of maturation stages in herring. J. Cons. Perm. Int. Explor. Mer, 29: 166-188.

JAKOBSEN, T., and A. AJIAD. 1999. Management implications of sexual difference in maturation and spawning mortality of northeast Arctic cod. J. Northw. Atl. Fish. Sci., 25: 125-131.

JAMIESON, B. G. M. 1991. Fish evolution and systematics: evidence from spermatozoa. Cambridge University Press, Cambridge, England, $319 \mathrm{p}$.

JORDAN, W. C., and A. F. YOUNGSON. 1992. The use of genetic marking to assess the reproductive success of mature male Atlantic salmon parr (Salmo salar, L.) under natural spawning conditions. J. Fish Biol., 41: 613-618.

JØRSTAD, K. E. 1986. Genetic studies connected with artificial propagation of cod (Gadus morhua L.). Aquaculture, 57: 227-238.

KIME, D. E., M. EBRAHIMI, K. NYSTEN, I. ROELANTS, E. RURANGWA, H. D.M. MOORE, and F. OLLEVIER. 1996. Use of computer assisted sperm analysis (CASA) for monitoring the effects of pollution on sperm quality of fish; application to the effects of heavy metals. Aquat. Toxicol., 36: 223-237.

KJESBU, O. S., J. KLUNGSØYR, H. KRYVI, P. R. WITTHAMES, and M. GREER WALKER. 1991. Fecundity, atresia and egg size of captive Atlantic cod (Gadus morhua) in relation to proximate body composition. Can. J. Fish. Aquat. Sci., 48: 2333-2343.

KJESBU, O. S., P. SOLEMDAL, P. BRATLUND, and M. FONN. 1996. Variation in annual egg production in individual captive Atlantic cod (Gadus morhua). Can. J. Fish. Aquat. Sci., 53: 610-620.

KJØRSVIK, E., A. MANGOR-JENSEN, and I. HOLMEFJORD. 1990. Egg quality in fishes. Adv. Mar. Biol., 26: $71-113$.

KJØRSVIK, E., and S. LØNNING. 1983. Effects of egg quality on normal fertilisation and early development of cod, Gadus morhua L. J. Fish Biol., 23: 1-12.

KOSIOR, M., and J. SKÓLSKY. MS 1992. Effect of variability in the sex ratio of cod on the population reproductive potential estimates. ICES C.M. Doc., No. 1992/J:18, 13 p.

LAHNSTEINER, F., B. BERGER, T. WEISMANN, and R. A. PATZNER. 1996. Motility of spermatozoa of Alburnus alburnus (Cyprinidae) and its relationship to seminal plasma composition and sperm metabolism. Fish Physiol. Biochem., 10: 167-179.

LAHNSTEINER, F., and R. A. PATZNER. 1998. Sperm 
motility of the marine teleosts Boops boops, Diplodus sargus, Mullus barbatus and Trachurus mediterraneus. J. Fish Biol., 52: 726-742.

LAHNSTEINER, F., T. WEISMANN, and R. A. PATZNER. 1997. Aging process of rainbow trout semen during storage. Prog. Fish-Cult., 59: 272-279.

LAHNSTEINER, F., T. WEISMANN, and R. A. PATZNER. 1998. An efficient method for cryopresevation of testicular sperm from the Northern pike, Esox lucius L. Aquacult. Res., 29: 341-347.

LAMBERT, Y., and J. -D. DUTIL. 1997a. Condition and energy reserves of Atlantic cod (Gadus morhua) during the collapse of the northern Gulf of St. Lawrence stock. Can. J. Fish. Aquat. Sci. 54: 2388-2400.

1997b. Can simple condition indices be used to monitor and quantify seasonal changes in the energy reserves of Atlantic cod (Gadus morhua)? Can. J. Fish. Aquat. Sci. 54 (Suppl. 1): 104-112.

LAMBERT, Y., and A. THORSEN. 2003. Integration of captive and wild studies to estimate egg and larval production of fish stocks. J. Northw. Atl. Fish. Sci., 33: 71-79 (this volume).

LAMBERT, Y., N.A. YARAGINA, G. KRAUS, G. MARTEINSDOTTIR, and P.J. WRIGHT. 2003. Using environmental and biological indices as proxies of egg and larval production of marine fish. J. Northw. Atl. Fish. Sci., 33: 115-159 (this volume).

LEUNG, L. K. P., and B.G.M. JAMIESON. 1991. Live preservation of fish gametes. In: Fish evolution and systematics: evidence from spermatozoa. B.G.M. JAMIESON (ed.). Cambridge University Press, Cambridge, England, p. 245-269.

LEVANDUSKI, M. J., AND J. G. CLOUD. 1988. Rainbow trout (Salmo gairdneri) semen: effect of non-motile sperm on fertility. Aquaculture, 75: 171-179.

LILLY, G. R. MS 1996. Condition of cod in Divisions 2J+3KL during the autumns of 1978-1995. Can. Sci. Adv. Sec. Doc., 96/65, 17 p.

Lilly, G. R., P. A. Shelton, J. BRATtEY, N.G. CADIGAN, E. F. MURPHY, and D. E. STANSBURY. MS 2000. An assessment of the cod stock in NAFO divisions 2J+3KL. Can. Sci. Adv. Res. Sec., 2000/063, $123 \mathrm{p}$.

LITVAK, M. K., and E. A. TRIPPEL. 1998. Sperm motility patterns of Atlantic cod (Gadus morhua) in relation to salinity: effects of ovarian fluid and egg presence. Can. J. Fish. Aquat. Sci., 55: 1871-1877.

LOCHMANN, S. E., G. K. MAILLET, K. T. FRANK, and C. T. TAGGART. 1995. Lipid class composition as a measure of nutritional condition in individual larval Atlantic cod (Gadus morhua). Can. J. Fish. Aquat. Sci., 52: 1294-1306.

MARCONATO, A., D. Y. SHAPIRO, C. W. PETERSEN, R. R. WARNER, and T. YOSHIKAWA. 1997. Methodological analysis of fertilization rate in the bluehead wrasse Thalassoma bifasciatum: Pair versus group spawns. Mar. Ecol. Prog. Ser., 161: 61-70.

MARKLE, D. F., and K. G. WAIWOOD. 1986. Fertilization failure in gadids: aspects of its measurements. J. Northw. Atl. Fish. Sci., 6: 89-93.
MARSHALL, C. T., O. S. KJESBU, P. SOLEMDAL, N. A. YARAGINA, and Ø. ULLTANG. 1998. Is spawner biomass a sensitive measure of the reproductive and recruitment potential of Northeast Arctic cod? Can. J. Fish. Aquat. Sci., 55: 1766-1783.

MARSHALL, C. T., N. A. YARAGINA, Y. LAMBERT, and O. S. KJESBU. 1999. Total lipid energy as a proxy for total lipid egg production by fish stocks. Nature, 402: 288-290.

MARSHALL, C. T., L. O'BRIEN, J. TOMKIEWICZ, G. MARTEINSDOTTIR, M. J. MORGAN, F. SABORIDO-REY, F. W. KÖSTER, J. L. BLANCHARD, D. H. SECOR, G. KRAUS, P. J. WRIGHT, N. V. MUKHINA, and H. BJÖRNSSON. 2003. Developing alternative indices of reproductive potential for use in fisheries management: case studies for stocks spanning an information gradient. J. Northw. Atl. Fish. Sci., 33: 161-190 (this volume).

MARTEINSDOTTIR, G., and G. A. BEGG. 2002. Essential relationships incorporating the influence of age, size, and condition on variables required for estimation of reproductive potential in Atlantic cod, Gadus morhua. Mar. Ecol. Prog. Ser., 235: 235-256.

MARTIN-ROBICHAUD, D. J., and M. A. ROMMENS. 2001. Assessment of sex and evaluation of ovarian maturation of fish using ultrasonography. Aquacult. Res., 32: $113-120$.

MATTHEWS, I. M., J. P. EVANS, and A. E. MAGURRAN. 1997. Male display rate reveals ejaculate characteristics in the Trinidadian guppy Poecilia reticulata. Proc. R. Soc. Lond., Ser. B: Biol. Sci., 264: 695-700.

MCCORMICK, M. 1998. Behaviorally induced maternal stress in a fish influence progeny quality by a hormonal mechanism. Ecology, 79: 1873-1883.

MEEKAN, M. G., and L. FORTIER. 1996. Selection for fast growth during the larval life of Atlantic cod Gadus morhua on the Scotian Shelf. Mar. Ecol. Prog. Ser., 137: 25-37.

METHVEN, D. A., and L. W. CRIM. 1991. Seasonal changes in spermatocrit, plasma sex steroids and motility of sperm from Atlantic halibut (Hippoglossus hippoglossus). In: Proceedings of the 4th international symposium on the reproductive physiology of fish. A. P. SCOTT, J. P. SUMPTER, D. E. KIME, and M. S. ROLFE (eds.). Fish. Symp. 91, Sheffield, UK, p. 170.

MJOLNEROD, I. B., I. A. FLEMMING, U. H. REFSETH, and K. HINDAR. 1998. Mate and sperm competition during multiple-male spawnings of Atlantic salmon. Can. J. Zool., 76: 70-75.

MORGAN, M.J. MS 2000. Estimating spawning stock biomass in $2 \mathrm{~J} 3 \mathrm{KL}$ cod using a cohort maturation model and variable sex ratio. Can. Sci. Adv. Sec. Doc., 2000/ $110,17 \mathrm{p}$.

MORGAN, M. J. and E. A. TRIPPEL. 1996. Skewed sex ratios in spawning shoals of Atlantic cod (Gadus morhua). ICES J. Mar. Sci., 53: 820-826.

MORGAN, M. J., C. E. WILSON, and L. W. CRIM. 1999. The effect of stress on reproduction in Atlantic cod. $J$. Fish Biol., 54: 477-488.

MORRISON, C. M. 1990. Histology of the Atlantic cod, 
Gadus morhua: an atlas. Part three. Reproductive tract. Can. Spec. Publ. Fish. Aquat. Sci., 110: 177 p.

MOULTON, S. M., and M. P. M. BURTON. 1999. Histological observations on spermatogenesis in winter flounder, Pleuronectes amercianus Walbaum, from Conception Bay, Newfoundland, Canada. Can. J. Zool., 77: $1682-1689$.

MOUNIB, M. S. 1978. Cryogenic preservation of fish and mammalian spermatozoa. J. Reprod. Fertil., 53: 13-18.

MUKHINA, N. V., C. T. MARSHALL, and N. A. YARAGINA. 2003. Tracking the signal in year-class strength of Northeast Arctic cod through multiple survey estimates of egg, larval and juvenile abundance. J. Sea Res., 50: $57-75$.

MURAWSKI, S. A., P. J. RAGO and E. A. TRIPPEL. 2001. Impacts of demographic variation in spawning characteristics on reference points for fishery management. ICES J. Mar. Sci. Symp. 58: 1002-1014.

MURUA, H., and F. SABORIDO-REY. 2003. Female reproductive strategies of marine fish species of the North Atlantic. J. Northw. Atl. Fish. Sci., 33: 23-31 (this volume).

NAGLER, J. J., and D. G. CYR. 1997. Exposure of male American plaice (Hippoglossoides platessoides) to contaminated marine sediments decreases the hatching success of their progeny. Environ. Toxicol. Chem., 16: 1733-1738.

NANTON, D. A., S. P. LALL, and M. A. MCNIVEN. 2001. Effects of dietary lipid level on muscle lipid deposition in juvenile haddock, Melanogrammus aeglefinus L. Aquacult. Res., 32: 225-234.

NISSLING, A., R. LARSSON, R., L. VALLIN, and K. FROHLUND. 1998. Assessment of egg and larval viability in cod, Gadus morhua: methods and results from an experimental study. Fish. Res., 38: 169-186.

NISSLING, A., and L. WESTIN. 1997. Salinity requirements for successful spawning of Baltic and Belt Sea cod and the potential for cod stock interactions in the Baltic Sea. Mar. Ecol. Prog. Ser., 152: 261-271.

NORDEIDE, J. T., and E. KJELLSBY. 1999. Sound from spawning cod at their spawning grounds. ICES J. Mar. Sci., 56: 326-332.

O'BRIEN, L., P. RAGO, P. BERRIEN, and R.G. LOUGH. 2003. Incorporating early-life history parameters in the estimation of the stock-recruit relationship of Georges Bank Atlantic cod (Gadus morhua). J. Northw. Atl. Fish. Sci., 33: 191-205 (this volume).

OHTA, H., K. KAWAMURA, T. UNUMA, and Y. TAKEGOSHI. 2001. Cryopreservation of the sperm of the Japanese bitterling. J. Fish Biol., 58: 670-681.

O'REILLY, P. T ., A. A. MCPHERSON, E. KENCHINGTON, C. TAGGART, M. W. JONES, and P. BENTZEN. 2002. Isolation and characterization of tetranucleotide microsatellites from Atlantic haddock (Melanogrammus aeglefinus). Mar. Biotechnol., 4: 418-422.

PANAGIOTAKI, P., and A. G. GEFFEN. 1992. Parental effects on size variation in fish larvae. J. Fish Biol., 41 (Suppl. B): 37-42.

PANINI, E. B., C. C. MYLONAS, S. ZANU, M. CARRILLO, J. RAMOS, and M. P. BRUCE. 2001. Incubation of embryos and larvae of marine fish using microtiter plates. Aquacult. Inter., 9: 189-195.

PEPIN, P., D. C., ORR, and J. T. ANDERSON. 1997. Time to hatch and larval size in relation to temperature and egg size in Atlantic cod (Gadus morhua). Can. J. Fish. Aquat. Sci., 54 (Suppl. 1): 2-10.

PETERSEN, C. W., R. R. WARNER, D. Y. SHAPIRO, and A. MARCONATO. 2001. Components of fertilization success in the bluehead wrasse, Thalassoma bifasciatum. Behav. Ecol., 12: 237-245.

RAJASILTA, M., J. PARANKO, and P. T. LAINE. 1997. Reproductive characteristics of the male herring in the northern Baltic Sea. J. Fish Biol., 51: 978-988.

RAKITIN, A., M. M. FERGUSON, and E. A. TRIPPEL. 1999a. Spermatocrit, spermatozoa density and size in Atlantic cod (Gadus morhua): correlation and variation during the spawning season. Aquaculture, 170: 349-358.

1999b. Sperm competition and fertilization success in Atlantic cod (Gadus morhua): effects of sire size and condition factor on gamete quality. Can. J. Fish. Aquat. Sci., 56: 2315-2323.

2001. Male reproductive success and body size in Atlantic cod Gadus morhua L. Mar. Biol., 138: 10771085.

RANA, K. 1995. Preservation of gametes. In: Broodstock Management and Egg and Larval Quality. N. R. Bromage and R. J. Roberts (eds.). University Press, Cambridge, p. 53-76.

RÄTZ, H.-J., and J. LLORET. 2003. Variation in fish condition between Atlantic cod (Gadus morhua) stocks, the effect on their productivity and management implications. Fish. Res., 60: 369-380.

RIDEOUT, R. M., and M. P. M. BURTON. 2000. The reproductive cycle of male Atlantic cod (Gadus morhua L.) from Placentia Bay, Newfoundland. Can. J. Zool., 78: 1017-1025.

RIDEOUT, R. M., M. P. M. BURTON, and G. A. ROSE. 2000. Observations on mass atresia and skipped spawning in northern Atlantic cod, Gadus morhua L., from Smith Sound, Newfoundland. J. Fish Biol., 57: 1429-1440.

RIDEOUT, R. M., M. K. LITVAK, and E. A. TRIPPEL. 2003. The development of sperm cryopreservation protocol for winter flounder Pseudopleuronectes americanus (Walbaum): evaluation of cryoprotectants and diluents. Aquacult. Res., 34: 653-659.

RIDEOUT, R. M., E. A. TRIPPEL, and M. K. LITVAK. In press. Paternal effects on haddock (Melanogrammus aeglefinus L.) early life history traits. J. Fish Biol.

RIDGWAY, M. S., B. J. SHUTER, and E. E. POST. 1991. The relative influence of body size and territorial behaviour on nesting asynchrony in male smallmouth bass, Micropterus dolomieui Lacépède (Pisces, Centrachidae). J. Anim. Ecol., 60: 665-681.

RIJNSDORP, A. D. 1990. The mechanism of energy allocation over reproduction and somatic growth in North Sea plaice, Pleuronectes platessa L. Neth. J. Sea Res., 25: 279-290.

RIJNSDORP, A. D., and B. IBELINGS. 1989. Sexual dimorphism in the energetics of reproduction and growth of North Sea plaice, (Pleuronectes platessa L.). J. Fish 
Biol., 35: 401-415.

ROBERTSON, D. R. 1996. Egg size in relation to fertilization dynamics in free-spawning tropical reef fishes. Oecologia, 108: 95-104.

ROFF, D. A. 1982. Reproductive strategies in flatfish; a first synthesis. Can. J. Fish. Aquat. Sci., 39: 1686-1698.

ROSENTHAL, H., D. KLUMPP, and J. WILLFUHR. 1988. Influence of sperm density and contact time on herring egg fertilization. J. Appl. Ichthyol., 4: 79-86.

SABORIDO-REY, F., and S. JUNQUERA. 1998. Histological assessment of variations in sexual maturity of cod (Gadus morhua L.) at the Flemish Cap (north-west Atlantic). ICES J. Mar. Sci., 55: 515-521.

SAILLANT, E., B. CHATAIN, A. FOSTIER, C. PRZYBYLA, and C. FAUVEL. 2001. Parental influence on early development in the European sea bass. J. Fish Biol., 58: $1585-1600$.

SCOTT, A. P., and S. M. BAYNES. 1980. A review of the biology, handling and storage of salmonid spermatozoa. J. Fish Biol., 26: 707-735.

SCOTT, W. B., and M. G. SCOTT. 1988. Atlantic fishes of Canada. Can. Bull. Fish. Aquat. Sci., 219: 731 p.

SHANGGUAN, B., and L. W. CRIM. 1999. Seasonal variations in sperm production and sperm quality in male winter flounder, Pleuronectes americanus: the effects of hypophysectomy, pituitary replacement therapy, and GnRH-A treatment. Mar. Biol., 134: 19-27.

SHAPIRO, D. Y., and L. A. GIRALDEAU. 1996. Mating tactics in external fertilizers when sperm is limited. Behav. Ecol., 7: 19-23.

SHELTON, P. A., D. E. STANSBURY, E. F. MURPHY, G. R. LILLY and J. BRATTEY. MS 1996. An assessment of the cod stock in NAFO Divisions 2J+3KL. Can. Sci. Adv. Sec. Doc., 96/80, 59 p.

SOROKIN, V. P. 1960. Sexual cycle and spermatogenesis in cod (in Russian). TR. PINRO, 12: 71-87.

STOCKLEY, P., M. J. G. GAGE, G. A. PARKER, and A. P. MØLLER. 1997. Sperm competition in fishes: the evolution of testis size and ejaculate characteristics. $\mathrm{Am}$. Nat., 149: 933-954.

STOSS, J. 1983. Fish gamete preservation and spermatozoa physiology. In: Fish physiology. W. S. Hoar, D. J. Randall and E. M. Donaldson (eds.). Vol. IXB. Academic Press, New York, p. 305-350.

SUQUET, M., R. BILLARD, J. COSSON, G. DORANGE, L. CHAUVAUD, C. MUGNIER, and C. FAUVEL. 1994. Sperm features in turbot (Scophthalmus maximus): a comparison with other freshwater and marine fish species. Aquat. Living Resour., 7: 283-294.

SUQUET, M., M. H. OMNES, Y. NORMA, and C. FAUVEL. 1992a. Assessment of sperm concentration and motility in turbot (Scophthalmus maximus). Aquaculture, 101: 177-185.

1992b. Influence of photoperiod, frequency of stripping and presence of females on sperm output in turbot, Scopththalmus maximus (L.). Aqua. Fish. Manag., 23: 217-225.

SUQUET, M., C. DREANNO, C. FAUVEL, J. COSSON and R. BILLARD. 2000. Cryopreservation of sperm in marine fish. Aquacult. Res., 31: 231-243.
SUQUET, M., C. DREANNO, B. PETTON, Y. NORMANT, M. H. OMNES, and R. BILLARD. 1998. Long-term effects of the cryopreservation of turbot (Psetta maxima) spermatozoa. Aquat. Living Resour., 11: 45-48.

TAKBORSKY, M. 1998. Sperm competition in fish: 'bourgois' males and parasitic spawning. Trends Ecol. Evolu., 13: $222-227$.

TEMPLEMAN, W., and V. M. HODDER. 1958. Variation with fish length, sex, stage of sexual maturity, and season in the appearance and volume of the drumming muscles of the swim-bladder in the haddock, Melanogrammus aeglefinus (L.). J. Fish. Res. Board Can., 15: 355-390.

TERJESEN; B.F., MANGOR-JENSEN, A., and FYHN, H.J. 1998. Ammonia dynamics in relation to hatching in Atlantic halibut (Hippoglossus hippoglossus L.). Fish Physiol. Biochem., 18: 189-201.

THORSEN, A., E.A. TRIPPEL, and Y. LAMBERT. 2003. Experimental methods to monitor the production and quality of eggs of captive marine fish. J. Northw. Atl. Fish. Sci., 33: 55-70 (this volume).

TOMKIEWICZ, J., M. ERIKSSON, T. BARANOVA, V. FELDMAN, and H. MÜLLER. MS 1997. Maturity ogives and sex ratios for Baltic cod: establishment of a database and time series. ICES C.M. Doc., No. 1997/ $\mathrm{CC}: 20,20 \mathrm{p}$.

TOMKIEWICZ, J., and F. W. KÖSTER. MS 1999. Maturation process and spawning time of cod in the Bornholm Basin of the Baltic Sea: Preliminary results. ICES C.M.Doc., No. 1999/Y:25, 19 p.

TOMKIEWICZ, J., L. TYBJERG, N. HOLM, A., HANSEN, C. BROBERG, and E. HANSEN. 2002. Manual to determine gonadal maturity of Baltic cod. DIFRES Report Series, Vol. 116:02. Danish Institute for Fisheries Research, Copenhagen. 49 p.

TOTH, G. P., S. A. CHRIST, H. W. MCCARTHY, J. A. TORSELLA, and M. K. SMITH. 1995. Computerassisted motion analysis of sperm from the common carp. J. Fish Biol., 47: 986-1003.

TRIPPEL, E. A. 1995. Age at maturity as a stress indicator in fisheries. BioScience, 45: 759-771.

1998. Egg size and viability and seasonal offspring production of young Atlantic cod. Trans. Am. Fish. Soc., 127: 339-359.

1999. Estimation of stock reproductive potential: history and challenges for Canadian Atlantic gadoid stock assessments. J. Northw. Atl. Fish. Sci., 25: 61-81.

TRIPPEL, E. A., M. J. MORGAN, A. FRÉCHET, C. ROLLET, A. SINCLAIR, C. ANNAND, D. BEANLANDS, and L. BROWN. 1997a. Changes in age and length at sexual maturity of Northwest Atlantic cod, haddock and pollock stocks, 1972-1995. Can. Tech. Rep. Fish. Aquat. Sci., 2157, 120 p.

TRIPPEL, E. A., O. S. KJESBU, and P. SOLEMDAL. 1997b. Effects of adult age and size structure on reproductive output in marine fishes. In: Early life history and recruitment in fish populations. R. C. Chambers and E. A. Trippel (eds.). Chapman and Hall, New York, p. 31-62.

TRIPPEL, E. A., and M. J. MORGAN. 1994a. Age-specific paternal influences on reproductive success in Atlantic 
cod (Gadus morhua) of the Grand Banks, Newfoundland. ICES Mar. Sci. Symp., 198: 414-422.

1994b. Sperm longevity in Atlantic cod (Gadus morhua). Copeia, 1994: 1025-1029.

TRIPPEL, E. A., and J. D. NEILSON. 1992. Fertility and sperm quality of virgin and repeat-spawning Atlantic cod (Gadus morhua) and associated hatching success. Can. J. Fish. Aquat. Sci., 49: 2118-2127.

TRIPPEL, E. A., C. M. DOHERTY, J. WADE, and P. R. HARMON. 1998. Controlled breeding technology for haddock (Melanogrammus aeglefinus) in mated pairs. Bull. Aquacul. Assoc. Can., 98-3: 30-35.

TVEDT, H. B., T. J. BENFEY, D. J. MARTIN-ROBICHAUD, and J. POWER. 2001. The relationship between sperm density, spermatocrit, sperm motility and fertilization success in Atlantic halibut, Hippoglossus hippoglossus. Aquaculture, 194: 191-200.

VLADIC, T., and T. JAERVI. 1997. Sperm motility and fertilization time span in Atlantic salmon and brown trout - The effect of water temperature. J. Fish Biol., 50: 1088-1093.

WANG, Z., and L. W. CRIM. 1997. Seasonal changes in the biochemistry of seminal plasma and sperm motility in the ocean pout, Macrozoarces americanus. Fish Physiol. Biochem., 16: 77-83.
WATANABE, W. O., and P. M. CARROLL. 2001. Progress in controlled breeding of summer flounder, Paralichthys dentatus, and southern flounder, P. lethostigma. J. Appl. Aqua., 11: 89-111.

WEDEKIND, C., R. MÜLLER, and H. SPICHER. 2001. Potential genetic benefits of mate selection in whitefish. J. Evol. Biol., 14: 980-986.

WESTIN, L., and A. NISSLING. 1991. Effects of salinity on spermatozoa motility, percentage of fertilized eggs and egg development of Baltic cod (Gadus morhua), and implications for cod stock fluctuations. Mar. Biol., 108: 5-9.

WOONINCK, L., J. E. STRASSMANN, R. C. FLEISCHER, and R. R. WARNER. 1998. Characterization of microsatellite loci in a pelagic spawner: the bluehead wrasse, Thalassoma bifasciatum. Mol. Ecol., 7: 1613-1621.

YANAGIMACHI, R., G. N. CHERR, M. C. PILLAI, and J. D. BALDWIN. 1992. Factors controlling sperm entry into the micropyles of salmonid and herring eggs. Dev. Growth Differ., 34: 447-461.

YARAGINA, N. A., and C. T. MARSHALL. 2000. Trophic influences on seasonal and interannual variation in the liver condition of Northeast Arctic cod (Gadus morhua). ICES J. Mar. Sci., 57: 42-55. 
